\title{
Methods for Calibration of Specimen Temperature During In Situ Transmission Electron Microscopy Experiments
}

Gaulandris, Fabrizio; Simonsen, Søren Bredmose; Wagner, Jakob Birkedal; Mølhave, Kristian; Muto, Shun; Kuhn, Luise Theil

Published in:

Microscopy and Microanalysis

Link to article, DOI:

$10.1017 / \mathrm{s} 1431927619015344$

Publication date:

2020

Document Version

Peer reviewed version

Link back to DTU Orbit

Citation (APA):

Gaulandris, F., Simonsen, S. B., Wagner, J. B., Mølhave, K., Muto, S., \& Kuhn, L. T. (2020). Methods for Calibration of Specimen Temperature During In Situ Transmission Electron Microscopy Experiments.

Microscopy and Microanalysis, 26(1), 3-17. https://doi.org/10.1017/s1431927619015344

\section{General rights}

Copyright and moral rights for the publications made accessible in the public portal are retained by the authors and/or other copyright owners and it is a condition of accessing publications that users recognise and abide by the legal requirements associated with these rights.

- Users may download and print one copy of any publication from the public portal for the purpose of private study or research.

- You may not further distribute the material or use it for any profit-making activity or commercial gain

- You may freely distribute the URL identifying the publication in the public portal 


\section{Methods for Calibration of Specimen Temperature during in situ Transmission Electron Microscopy Experiments}

Fabrizio Gaulandris ${ }^{a}$, Søren Bredmose Simonsen, ${ }^{a}$ Jakob Birkedal Wagner ${ }^{b}$, Kristian Mølhave ${ }^{b}$, Shun Muto $^{c}$, Luise Theil Kuhn ${ }^{a}$

${ }^{a}$ Department of Energy Conversion and Storage, Technical University of Denmark, Fysikvej, DK-2800 Kgs. Lyngby, Denmak

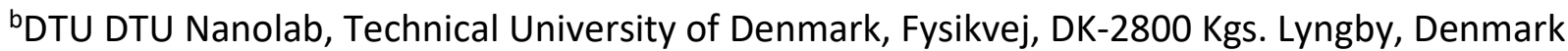

'Institute of Materials and Systems for Sustainability, Nagoya University, 464-8601 Furocho, Chikusa-

ku, Nagoya, Aichi, Japan

*corresponding author: sobrs@dtu.dk, Phone +45 20120611 


\begin{abstract}
One of the biggest challenges for in situ heating transmission electron microscopy (TEM) and scanning transmission electron microscopy (STEM) is being able to measure the local temperature of the specimen accurately. Despite technological improvements in the construction of TEM/STEM heating holders, the problem of being able to measure the real sample temperature remains intensively discussed. In this study we review the present literature on methodologies for temperature calibration. We analyze calibration methods that require the use of a thermometric material in addition to the specimen under study, as well as methods that can be performed directly on the specimen of interest without the need for a previous calibration. Finally, an overview of the most important characteristics of all the treated techniques, including temperature ranges and uncertainties, is provided in order to provide an accessory playground to consult before an in situ TEM/STEM temperature calibration experiment.
\end{abstract}

Keywords: Transmission electron microscopy, Temperature calibration, In situ, heating experiment, MEMS, Heating holder 


\section{Introduction}

Transmission electron microscopy (TEM) and scanning transmission electron microscopy (STEM) are typically used for ex situ characterization of nano- and atomic scale structures. Since the recorded electron signal is transmitted through the specimen, the specimen has to be thin enough for electron transparency, typically on the order of $100 \mathrm{~nm}$. Despite this demanding geometrical restriction on the specimen, various types of in situ experiments have been performed inside TEMs/STEMs, for instance, heating experiments in vacuum (Watanabe, 1956; Thornburg \& Wayman, 1973; Wang et al., 1998; Asoro et al., 2010; Ida et al., 2010; Yonezawa, 2009; Walsh et al., 2009) and so-called controlled atmosphere or environmental TEM/STEM experiments with chemical reactions in gases at elevated temperature (Baker \& Harris, 1972; Heinemann \& Poppa, 1976; Hansen et al., 2002; Crozier \& Datye, 2000; Helveg et al., 2004; Wang et al., 2006; Yoshida et al., 2012). Heating experiments in vacuum offer insight in, e.g., nanoparticle morphology and melting during annealing (Ida et al., 2010; Yonezawa, 2009), amorphization (Holloway \& Sinclair, 1988), and nanoparticle coarsening (Heinemann \& Poppa, 1976, Simonsen et al. 2010). Heating experiments in reactive gases have proven to be a powerful approach to observe nanoscale reaction dynamics of, for example, oxidation (Baker \& Harris, 1972; Simonsen et al., 2009; Rackauskas et al. 2014), reduction (Crozier \& Datye, 2000, Simonsen, 2015), growth of carbon nanotubes (Baker \& Harris, 1972; Helveg et al., 2004, Zhang et al., 2017), crystallite morphology dependence on gas environment (Hansen et al., 2002), and coarsening of nanoparticles (Baker et al., 1975; Fujita et al., 2012; Simonsen et al., 2012; Simonsen et al., 2016).

In situ TEM heating experiments have been conducted since the 1960's (Valdré \& Goringe, 1965). In such experiments, it is essential to be able to measure the temperature of the specimen, and to be able 
to check and calibrate the temperature measurements. In this paper, we review methods for calibrating temperatures within a TEM/STEM. Given the absence of a comprehensive review to date on this topic, after a brief overview of heating holder systems, this review aims to cover: i) direct temperature readout methods, ii) calibration methods, and iii) the challenges arising due to the local electron beam heating, reactions or surrounding gas cooling the specimen. Detailed reviews on specific topics have covered the environmental TEM (Hansen \& Wagner, 2016), thermally activated material reactions (Sinclair, 2013), environmental STEM studies of gas-liquid-solid interactions (Gai et al., 2008), nanotechnology (Wang, 2003; Sharma \& Crozier, 2005), catalysis measurements (Han et al., 2015; Taheri et al., 2016), and electrochemical devices (Harks et al.,2015).

\section{Overview of heating holders}

While commercial microfabricated TEM/STEM heating systems are gaining popularity, replacing the traditional furnace based holders, custom-made microfabricated devices were used to study nanowire growth (Jacobsson et al., 2015), thermal conductivity of nanostructures (Lee et al., 2017), and even enabling in situ TEM/STEM growth and characterization of silicon nanowire devices (Panciera et al., 2016; Alem et al., 2015). In the conventional types of TEM/STEM holders, the specimen is typically heated by the use of a cylindrically shaped furnace containing a heater filament (Swann, 1978). As can be seen in Figure 1a, this type of furnace is several millimeters in diameter to hold a standard sized TEM/STEM grid. The temperature is monitored by a thermocouple attached to the furnace. With this setup, the actual temperature of the specimen may deviate from the read-out of the thermocouple, because of temperature gradients from the furnace to the specimen. Additionally, one also has to consider the possible local heating from the electron beam. Temperature gradients will depend on the 
thermal conductivity of the specimen itself, the location of the specimen on the support, thermal conductivity of the support, and heat conduction by the surrounding gases, further complicating the situation because these parameters may vary with time as thermal equilibrium is established (Baker \& Harris, 1972). Another type of traditional TEM/STEM heating holder is the so-called Kamino holder where a powder specimen is added directly to a filament, and the temperature of the filament is calibrated beforehand, e.g., using a pyrometer (Kamino \& Saka, 1993). In some cases, the heater is coated with a carbon support film. When nano-sized powder is in direct contact with the much larger filament (thickness of ca. 25 microns) (Kamino \& Saka, 1993), it is reasonable to assume that the temperature of the nano-particles is identical to that of the filament when thermal equilibrium is reached. To some extent, the same argument also applies for the traditional cup-furnace holder (Figure 1a) where the furnace is large compared to the TEM/STEM grid, which will, assuming good heat conductance and negligible cooling by gas around the cup, have a temperature close to that of the furnace. For both types of traditional holders there may be temperature gradients in the specimen itself, if agglomerates are sticking out from the support, and if insufficient thermal conductivity exists across the contact area to the TEM/STEM grid (Winterstein et al., 2015). If the holder has no direct temperature feedback from a thermocouple, a separate temperature calibration will have to be performed in vacuum, and in the case of environmental TEM, for each different gas type and pressure.

A major disadvantage of traditional TEM/STEM heating holders is that they induce mechanical drift of the specimen during temperature ramping because of thermal expansion of the materials involved. Consequently, it can be a challenge to achieve quality images or analysis before thermal equilibrium is reached, and reactions may have taken place. In addition, the furnace will slowly heat the rod of the 
TEM/STEM holder, despite effort to isolate it thermally, and thermal expansion of the rod results in a slow continuous drift of the specimen. Attempts have been made to minimize this effect by adding water-cooling of the TEM/STEM holder rod, but this often induces an oscillation type of drift of the specimen from the pumped water flow (Banhart, 2008). Moreover, the large amount of mass to be heated generates intense infrared radiation that limits the utilization of an X-ray energy-dispersive spectroscopy (EDS) detector, which is easily saturated when the temperature of the holder is increased.

Recently, micro-electromechanical system (MEMS) devices have been implemented in TEM/STEM heating holders (Allard et al., 2009; Zhang et al., 2017; Chang et al., 2017; Burke et al., 2017; Fei et al., 2016, Chen et al., 2017; Steinhauer et al., 2017). Figures 1b-c show examples of MEMS chip designs for TEM/STEM heating holders. The commercial chip presented in Figure $1 \mathrm{~b}$ includes a heater spiral to elevate the temperature by resistive heating. The custom fabricated chip presented in Figure $1 c$ has two flexible microcantilever loops extending freely into the vacuum. The temperature is elevated by Joule heating by currents passing through each cantilever. A voltage difference can be applied between the two cantilever loops to apply a potential to the specimen for electrical measurements. There are also commercially available chip-based heating-biasing holders using the concept of a heater spiral (Figure $1 b$ ) or a heat conductive thin membrane. Several other MEMS chip designs are available (Hattar et al., 2004, Bernal et al., 2015, Yang et al., 2019).

There are four major advantages of the MEMS-based heating holders: i) They allow very high heating and cooling rates $\left(1000^{\circ} \mathrm{C}\right.$ in $1 \mathrm{~ms}$ (Allard et al., 2009)). ii) The specimen drift is significantly reduced compared to the traditional holders, with sample drift rates down to less than $1 \mathrm{~nm} / \mathrm{min}$. The reason for both (i) and (ii) is that the heated volume is much smaller (nano- to micro-meter scale) compared 
with the traditional furnace types (millimeter scale). iii) The MEMS technology offers a high degree of flexibility in design, which includes possibilities for combinations of heating with other experimental conditions. The cantilever tweezer-style designs (Figure 1c) for example offer the possibility of a combination of heating and electrical biasing of a specimen. iv) The heat radiation from the MEMS heaters is much smaller than from traditional holders, and there is no large furnace cup to block EDS signals. This makes it possible to perform EDS analysis at elevated temperatures with the MEMS-based heaters. The temperature of the MEMS-based holders is typically calibrated based on resistance measurements.

While a relatively small heated region is an advantage for reducing drift and obtaining high temperature ramping rates, it can be a disadvantage that the size of the specimen is more comparable to the size of the heater. The temperature distributions in MEMS devices are therefore not as uniform as for the traditional holders (Winterstein et al., 2015; Niekiel et al., 2017). For MEMS-based heating holders with a heater spiral, such as the one presented in Figure $1 \mathrm{~b}$, achieving a homogeneous temperature distribution requires a delicate balance of joule heat dissipation with heat loss through surrounding gas and thermal radiation. The temperature can easily become higher for a specimen placed at the center of the spiral than at the edge.

In addition to specimen heating by a furnace in the holder, other heating methods exist. One example is heating with laser pulses which is, for example, used in ultrafast imaging (Grinolds et al. 2006). This type of heating is preferable for fast imaging because is it possible to precisely time initiation of the heating with the fast imaging. Another specialized heating method is electroburning which is used, for example, in studies of graphene as an electrode material. Localized heating induced by an electrical 
current introduces nano-gaps in the graphene (Candini et al. 2015). It is beyond the scope of the present work to review temperature calibration of these more specialized heating methods.

\section{Gases}

TEMs/STEMs that are dedicated for gas environment experiments have become commercially available in the last two decades, and the number of TEM/STEM studies at elevated temperatures in reactive gases is rapidly increasing. When heating holders are used in the presence of a surrounding gas (typically with a pressure of a few mbars), there will be an additional loss of heat to the surrounding gas, and the heating holder is not necessarily calibrated for such an environment (Winterstein et al., 2015). The heat conductance also depends on the type of gas, which means that it is necessary to perform the calibration in both the relevant gas composition and pressure.

\section{Direct temperature read-out}

Most, but not all, TEM/STEM heating holders will give a temperature or voltage/current read-out. The temperature of traditional TEM/STEM heating holders is monitored either from the voltage/current applied to the holder or from a thermocouple welded onto the furnace (Figure 1a). In the first case, a calibration is needed to relate the voltage/current to the actual temperature of the furnace. In commercial MEMS-based TEM/STEM heating chips, the temperature read-out is obtained by measuring the resistance in the heater element, since this will vary as a function of temperature. In both types of holders, the temperature is calibrated to the power input by the manufacturer, for example by using an optical pyrometer or a Raman spectrometer while heating the device in vacuum (Allard et al., 2009). The result is a temperature curve as a function of input current. 
The direct temperature read-out is therefore based on calibrations performed by the manufacturer under specific conditions. If, however, the holder is used under different conditions, e.g., in a gas environment, where the gas will conduct heat away from the furnace, then the actual temperature of the specimen will be different from the pre-calibrated temperature (Baker \& Harris, 1972). When using TEM/STEM grids or support films with low thermal conductivity, the temperature of the specimen can also deviate from that of the heater element. The microscopist will therefore need to calibrate the temperature to the power input under relevant conditions. In the following, different methods for temperature calibrations are reviewed.

\section{Temperature calibration methods}

In this section, we review temperature calibration methods that have been used to locally calibrate temperature in TEM/STEM heating experiments. The first methods are based on the use of a thermometric materials, i.e., materials that chance properties at specific temperatures and therefore can be used to indicate a temperature (melting points, crystal phase transition, magnetic structure, thermal expansion, second phase dissolution, and gas-solid chemical reactions). Methods not based on thermometric materials are then presented (vibrational spectroscopy, thermal diffuse scattering, and changes in the plasmon signal). A section for each method provides an overview of the principle, materials, and challenges.

\section{Methods based on thermometric materials}




\section{Melting point}

Principle

A series of measurements of melting points of pure elements or well-characterized alloys is one method for temperature calibration. The melting points of different elements are well-known in the literature, and therefore represents a reliable reference. The ordered structure of the solid crystal breaks down at the melting point. Such ordered structures can be observed in the TEM, for example as distinct spots in electron diffraction patterns, or as lattice fringes in HRTEM images. Therefore, the transition from solid to liquid can be observed experimentally both in diffraction and imaging mode. In diffraction mode, the distinct diffraction spots will disappear at the melting point. In image mode, lattice fringes will disappear. Alternatively, for certain specimens it is also possible to investigate the melting transition by observing the intensity change in dark-field images (Brintlinger et al., 2008). For example, Brintlinger et al. (Brintlinger et al., 2008) deposited indium islands on the reverse side of a commercially available silicon nitride membrane. With the use of dark-field images, the authors determined the melting transition of each island by observing their local intensity change. Since the temperature was not uniformly distributed on the membrane, it was possible to use this technique as a nanoscale thermal mapping from the response at individual islands' location. Moreover, the melting point changed with the size of the nanoparticle, a phenomenon first described by Pawlow in 1909 (Ven \& Pawlow, 1910). The melting point decreases with decreasing particle size, a phenomenon called melting point depression (Sambles, 1971; Buffat \& Borel, 1976; Allen et al., 1986). This effect is due to the increased surface-to-volume ratio. Atoms at a surface have fewer neighbors compared to bulk atoms, and therefore have relatively lower cohesive energies. The cohesive energy of an atom is directly 
related to the thermal energy required to free the atom from the solid (Nanda et al., 2002). To calibrate temperature by using nanoparticles, it is therefore necessary to determine the size-dependent melting point function for the specific type of nanoparticle. This can theoretically be determined from the equation (Reiss et al., 1988),

$$
T_{N P M P}(d)=T_{B M P}\left(1-\frac{\beta}{d}\right)
$$

where $T_{N P M P}$ is the melting point of the nanoparticle, $T_{B M P}$ the bulk melting point, $d$ the nanoparticle diameter, and $B=\sigma v / \Delta H_{f}$, where $\sigma=$ the solid-liquid interface energy, $v=$ the volume of an atom in the liquid phase, and $\Delta H_{f}=$ the bulk heat of fusion (Reiss et al., 1988). Figure 2 presents the size-dependent melting point for the metals presented in Figure 3.

Choice of materials

For a given experiment, materials with different melting points in the temperature range of interest need to be found. Figure 3 show examples of metals and alloys that have been melted previously in a TEM (Wang et al., 1998; Asoro et al., 2010; Ida et al., 2010; Yonezawa, 2009; Walsh et al., 2009; Baker \& Harris, 1972). Due to the relatively high melting point of most metals, there are few pure metals to use for calibration in the temperature range $400-900{ }^{\circ} \mathrm{C}$ where many interesting reactions have been studied by in situ TEM (Helveg et al., 2004; Peng et al., 2012; Diaz et al., 2012; Jeangros et al., 2016). If the experiments are conducted in the presence of reactive gases, it is important to choose materials that do not react with the gas phase to change the chemical state of the element. For example, some metals, such as $\mathrm{Al}, \mathrm{Cu}$, or $\mathrm{Ni}$, will form oxides in the presence of oxygen at temperatures below the melting point, and the oxides have far higher melting points. This must be taken into consideration in 
the presence of oxygen. In addition to chemical reactions with the gas phase, the specimen might react chemically with the specimen support during the heating experiment to form a compound with a different melting point. It is also always important to choose materials that are stable in the electron beam, so that the crystal structure is not disrupted due to beam damage.

Specimen geometry

Melting point measurements have been performed for bulk materials thinned sufficiently for electron transparency (Agar \& Lucas, 1962), supported nanoparticles (Revina et al., 2007, Simonsen et al., 2015; Winterstein et al., 2015), and for 2D nano-islands (Brintlinger et al., 2008). Thinned bulk materials were analyzed by Agar and Lucas to calibrate the temperature in a TEM furnace heater (Agar \& Lucas, 1962), e.g., indium, tin, lead, zinc, aluminum, silver, copper, and lead. Swann et al. (Swann et al., 1978) used a thin foil metal alloy of Al-Cu, looking at the eutectic melting point. Nanoparticles have also been used to calibrate the temperature within a TEM taking the size dependence described by equation 1 into account (Revina et al., 2007; Simonson et al., 2015). Simonsen et al estimated an error of $\pm 25^{\circ} \mathrm{C}$ when calibrating using Ag and Zn nanoparticles (Simonsen et al., 2015). In comparison with thin foils, a TEM specimen of nanoparticles generally requires less preparation time.

Lan et al. (Lan et al., 2013) showed the possibility of using PbTe nanocubes as temperature calibration standards. Melting is initiated at cube corners and the particle morphology is gradually changed as the temperature is raised. Therefore, the same material can be used to identify a range of melting temperatures, not just one, as in the case of nanoparticles. Nanocubes' morphology variations were first studied by ex-situ TEM to correlate temperatures and the specimen morphology change. The different geometry of the nanocubes compared to nanoparticles considered in equation 1 lies outside 
the assumption of spherical particle geometry. Nanocubes of Ag where also used by Vijayan et al. to calibrate the temperature of a MEMS heating holder (Vijayan et al., 2019).

\section{Challenges}

A challenge related to the employment of nanoparticles is thermally activated mobility at high temperatures below the melting point. Rotational movements can result in loss of lattice fringes observed by HRTEM images, and this can be incorrectly interpreted as melting. The issue of nanoparticle mobility can be circumvented by using a thin foil material specimen instead. However, this will require more time and effort for specimen preparation, and these thinned specimens can also be challenging to mount on MEMS heater chips.

\section{Crystal phase structure transition}

Principle

It is well-known that the specific crystal structure of a given material often depends on the temperature and pressure (Sinclair \& Parker, 1986; Holloway \& Sinclair, 1988), and the temperature interval in which the crystal structure changes can be relatively narrow. Since changes in crystal structures can be determined from electron diffraction patterns or from HRTEM imaging, observations of crystal phase transformations can be used for temperature calibration. An example of such a temperature calibration was conducted by Bonneaux and Guymont (Bonneaux \& Guymont, 1999). They studied the series of transitions that AuCu alloy undergoes with temperature. The results were compared with literature results obtained via XRD analysis. A recent example from Bayat et. al (Bayat et al., 2017) is the study of temperature-dependent transformations of $\mathrm{Mg}_{2} \mathrm{Si}$ and $\alpha-\mathrm{Al}(\mathrm{FeMn}) \mathrm{Si}$ in 6005 and 6082 Al alloys. Another example is epitaxial re-growth. Here the principle is that the crystal phase is maintained, but 
defects in the crystal are removed by thermally activated re-growth. Sinclair and Parker have, for example, observed silicon solid-phase epitaxial re-growth (SPER) in situ (Sinclair \& Parker, 1986). They used ion-implantation to produce an amorphous silicon structure, after which they performed an annealing treatment in the TEM to produce a virtually defect-free single crystal structure (Sinclair \& Parker, 1986). This process is a thermally activated phenomenon, and silicon has an established activation energy of $2.7 \mathrm{eV}$ (Roth et al., 1990). Therefore, by observing the gradual advance of the crystalline-amorphous interface within a TEM, it is possible to estimate the re-growth velocity at a certain temperature and compare the results with literature to obtain a calibrated temperature. Stach et al. used this method to calibrate the thermocouple reading of a TEM holder, as shown in Figure 4 (Stach et al., 1998). Repeating the experiment at different temperatures, they were able to calibrate the temperature over a range between $500^{\circ} \mathrm{C}$ and $650^{\circ} \mathrm{C}$.

Another variation of using changes in crystal structure for temperature calibration is using the temperature dependency of the ordering of atoms intercalated in a crystal structure. For example, Chung et al. observed the order-disorder transformation of $\mathrm{Br}_{2}$ or IC1 intercalated in graphite using electron diffraction (Chung, 1978) and were able to calibrate the temperature of a TEM specimen holder (Chang et al., 2017). The order-disorder transformation can be observed from the disappearance of superlattice diffraction spots. One of the advantages of the method is the relatively simple specimen preparation. These compounds are layered materials, and they can be easily cleaved in order to obtain an electron transparent specimen. The two temperatures calibrated by the authors were essentially two, $100 \pm 1{ }^{\circ} \mathrm{C}$ for graphite- $\mathrm{Br}_{2}$ and $41 \pm 1{ }^{\circ} \mathrm{C}$ for graphite-IC1. Another example is the metal-insulator 
transition at $68^{\circ} \mathrm{C}$ in $\mathrm{VO}_{2}$ nanowires that can be observed in diffraction patterns. This can be used to study local temperatures, even along a nanowire if heated by the incident beam (Guo et al., 2014).

Choice of materials

Figure 5 presents examples of materials for which a temperature-dependent phase change has been observed in a TEM. There are many more examples in the literature. What can make it somewhat complicated to choose a suitable material is that the reported materials are often special in the sense that either the geometry, composition or both are complex. It can, therefore, be time consuming to prepare a suitable calibration specimen. It is important to make sure that the expected phase change is not pressure-dependent, which can make it difficult to compare reference data obtained at ambient pressure with experiments performed in the vacuum of the TEM. If the experiments are conducted in the presence of reactive gases, it is important to choose materials that do not react with the gas.

\section{Challenges}

If a powder specimen on a support film is used, then thermal activated mobility can cause rotation of the nanoparticles out of the zone axis, and this can be wrongly interpreted as a change in crystal phase. A double-tilt holder is often used when studying the crystal structure at a zone axis, but this option is only available for some types of heating holders. Concerning the epitaxial re-growth, the activation energy, and thereby the re-growth rate, can be affected by the presence of impurities (Roth et al., 1990). 


\section{Magnetic structure}

Principle

Ferro (and ferri-) magnetic materials lose their magnetic order above the Curie temperature. The Curie point can therefore be used as a temperature calibration point. Martin and Boyd proposed a method for such a temperature calibration based on the TEM image displacement caused to a specimen with ferro (and ferri-) magnetic moment (Martin \& Boyd, 1973). A series of a pair of images is acquired at different temperatures, one in focus and one over-focused (Figure 6). A feature on the specimen is used as a reference to calculate displacement between the two images. Once the displacement becomes zero, the Curie temperature is reached. The analysis was performed with a Ni foil specimen (Martin \& Boyd, 1973). This experiment represents a simple method to calibrate an absolute temperature. On the other hand, an additional foil of $\mathrm{Ni}$, beside the specimen, was necessary in order to increase the overall magnetic effect from the specimen, since the magnetic field of the thin foil alone was not enough to bring any visible image displacement.

\section{Choice of materials}

Besides $\mathrm{Ni}$, the same experiment can be performed with any ferromagnetic material, for example, Fe $\left(\mathrm{T}_{\mathrm{C}}=770^{\circ} \mathrm{C}\right)$ and $\mathrm{Co}\left(\mathrm{T}_{\mathrm{C}}=1125^{\circ} \mathrm{C}\right)$, covering a wider temperature calibration range. Figure 7 presents Curie points for a variety of materials. It should be mentioned that this method is sparse in the literature and most of the materials in Figure 7 have not yet been applied for TEM temperature calibrations. It should be noticed that oxides can be used besides metals, which makes it possible to perform the calibration in the presence of an oxidizing gas. 


\section{Challenges}

The force between the magnetic specimen and the magnetic field of the objective lens can be so strong that the specimen is pulled off the specimen holder. When working with a magnetic specimen, it is therefore important that the specimen is securely fixed to the specimen holder. A thinned disk of the magnetic material can, for example, be safely secured in the type of heating holder presented in figure $1 \mathrm{a}$, where a screw is making sure that the specimen cannot fly off. It is, however, more difficult to securely fix the specimen to the heater spiral of the Kamino holder or to a MEMS-based chip. This therefore sets a limit to the application of this calibration method.

\section{Thermal expansion}

Principle

Most materials undertake volume expansion when heated. The atomic vibrational motion increases, leading to an increase in mean separation, i.e., expansion of the crystal lattice. The relation is linear for isotropic solids, unlike anisotropic solids and can be described by equation 2 (Suh et al., 1988):

$$
\frac{\Delta l}{l_{0}}=\alpha_{1} \Delta T+\alpha_{2} \Delta T^{2}
$$

where $\Delta /$ is the change in length, $l_{0}$ the initial length, $\Delta T$ the change in temperature, and $\alpha_{1}$, and $\alpha_{2}$ are the linear expansion coefficients. In the past, in situ X-ray diffraction has been used to measure thermal lattice expansions of metals with an accuracy between 1 to $20^{\circ} \mathrm{C}$ (Simmons, 1970; Gao, 2003). Similarly, lattice expansion can be measured by TEM in diffraction mode observing changes in the separation of diffraction spots (Cremons \& Flannigan, 2016). Winterstein et al. (Winterstein et al. 2014) used selected area electron diffraction (SAED) in an ETEM to measure the lattice expansion of Ag nanoparticles by 
observing changes in the ring diameter from room temperature to $500{ }^{\circ} \mathrm{C}$ (Figure 8). In a recent study, the temperature gradient across the TEM heating chip was measured by diffraction using differences in thermal expansion of the lattice of Au nanoparticles (Niekiel et al., 2017). The advantage of this method, compared to using melting points, is that several measurement points can be measured for the same reference specimen.

Choice of materials

The preferred material should have a large linear expansion coefficient in order to provide a measurable shift in the diffraction patterns. Figure 9 presents the relation between lattice expansion and temperature. Here it can be seen that the metals $\mathrm{W}, \mathrm{Ag}, \mathrm{Mo}$, and $\mathrm{Cu}$ have a larger expansion than for example Ni. The chosen material should also have a high melting point in order to cover a wider range of temperature. According to Figure 9, the measured expansion by XRD for Ag and Cu agrees well with eq. 2 in the temperature range between $300^{\circ} \mathrm{C}$ and $1000^{\circ} \mathrm{C}$.

\section{Challenges}

The measured shift in diffraction ring diameter is continuous and small. According to Figure 8 , the shift of the diffraction spots for $\mathrm{Ag}$ and $\mathrm{Cu}$ is only ca. $1 \%$ for a temperature interval of $500{ }^{\circ} \mathrm{C} \mathrm{A}$ shift on this order (ca. $0.01 \AA$ ) was observed in the study of Ag by Winterstein et al. (Winterstein et al., 2014). Therefore, diffraction patterns of good quality need to be recorded and precise centering and rotational averaging and fitting is needed. In the study by Winterstein et al. (Winterstein et al., 2014) an error of $\pm 30{ }^{\circ} \mathrm{C}$ was estimated for Ag. Another option is to measure the thermal expansion directly, as done with carbon nanotubes partly filled with gallium (Gao, 2003; Gong et al., 2008) or Sn in ZnO (Ortega et al. 2010), which can function as nanoscale thermometers and also be used ex situ and under oxidizing 
conditions, where the eventually formed oxide cap will also serve as an indicator of the maximum temperature reached in the process (Gao et al., 2003).

\section{Second-phase dissolution}

Principle

Within alloys, metals may separate into distinct phases at specific temperatures. The transformation temperature for an alloy with a given composition is described by the so-called solvus line on the phase diagram. Alloys with elements present in an intermetallic mixture can therefore be used for temperature calibration by imaging dissolution/separation processes. Such a second-phase dissolution was used by Butler and Hale to calibrate the temperature in a TEM (Butler \& Hale, 1981). They used an Al-Cu alloy containing 4.5 wt. $\% \mathrm{Cu}$ with a solvus temperature of $520^{\circ} \mathrm{C}$. They observed second-phase dissolution of precipitates situated at the grain boundaries.

Choice of materials

The material can be any alloy with an intermetallic mixture and a solvus temperature in the desired range. This will typically be alloys of metals with different crystal structures, since these tend to form the needed intermetallic state.

\section{Challenges}

TEM/STEM is applied for analysis of only small fractions of the bulk intermetallic specimen. It can therefore be questioned if the small volume of the TEM specimen has the same overall composition as the bulk alloy. 


\section{Gas-solid chemical reactions}

Principle

Chemical reactions, such as reduction or oxidation, are often activated by elevating the temperature, and the reaction rate depends exponentially on the temperature, as described by the Arrhenius equation. Observation of reaction kinetics in the TEM/STEM can, therefore, be used for temperature calibration provided that it is possible to compare in situ TEM/STEM results with results from other types of chemical reactors, where the temperature measurements are considered reliable. For example, Simonsen et al. used a non-catalytic oxidation profile of carbon black to verify the reliability of the temperature read-out of a cup-based heating holder operated in 2 mbar $\mathrm{O}_{2}$ (Simonsen, 2008). A similar example is the decomposition of the polymer PVP, which takes place between $350{ }^{\circ} \mathrm{C}$ and 400 ${ }^{\circ} \mathrm{C}$ when ramping the temperature by $10^{\circ} \mathrm{C} / \mathrm{min}$ in 2 mbar oxygen (Simonsen et al., 2017). In hydrogen, the reduction of an oxide can be used, for example $\mathrm{NiO}$ reduction, for which the onset temperature can be observed at $300^{\circ} \mathrm{C}$ when ramping the temperature by $1^{\circ} \mathrm{C} / \mathrm{min}$ in $2 \mathrm{mbar} \mathrm{H}_{2}$ (Simonsen et al., 2015). In all of these examples, reference experiments had to be performed in a different reactor to confirm the onset temperature with the same type of sample, same temperature profile (Jeangros et al., 2013), and similar oxygen or hydrogen gas pressure. The need to perform such reference experiments means that this method is also relatively time consuming. The main advantage of this method is that it can be used in reactive gas environments, where it can be difficult to calibrate by the previously discussed methods because solid-gas reactions change the specimen properties. 
Choice of materials

In principle, any material which can react at the available gas pressure in the TEM, can be used for this type of calibration.

\section{Challenges}

Chemical reactions often depend both on the temperature and gas pressure. When comparing the in situ TEM reduction/oxidation with results from a different type of reactors the two reactions should therefore be performed in the same total gas pressure and composition for pressure-dependent reactions. When using a TEM with a differential pumping system, this requirement is, however, often not practically possible to fulfil because most other chemical reactors are operated at a pressure of 1 bar or above. Instead of using the same total pressure in the two reactors, it is often sufficient to use the same partial pressure of the reactive gas. Also, the same temperature ramping rate should be applied.

\section{Methods not involving thermometric materials}

In this section, we describe alternatives to the use of thermometric materials. Advantages are that the calibration can be performed directly with the actual material to be studied without needing a calibration specimen. In addition, this can reduce the time spend on temperature calibration, the methods can be performed in both vacuum and any gas environment, and there will therefore be no cross-contamination between the actual specimen and the calibration specimen. 


\section{Vibrational and optical spectroscopy}

Principle

Raman spectroscopy is a well-known method to study vibrational, rotational and other low-frequency modes in a system. Picher et al. (Picher et al., 2015) were able to perform in situ TEM Raman spectroscopy measurements. They inserted an optical spectroscopy system inside an environmental STEM, between the specimen holder and the lower objective pole piece. The main component was represented by a parabolic mirror able to focus light on the specimen from an external source and also collect the specimen response. The setup was used to calibrate the temperatures by measuring the Raman peak shift with temperature of a single-wall carbon nanotube (SWCNT). The authors were able to calibrate temperature in the interval between $200^{\circ} \mathrm{C}$ and $900{ }^{\circ} \mathrm{C}$.

Choice of materials

The specimen must have an observable Raman peak in order to be measured. SWCNTs for example provide high surface contact with the substrate, they have high thermal conductivity and they have a sharp $\mathrm{G}$ band in Raman spectra.

Challenges

The method depends on the integration of a sophisticated additional instrumentation in the TEM. The spatial resolution is limited by the laser spot size. This was $11 \pm 4 \mu \mathrm{m}$ in the case of Picher et al. (Picher et al., 2015). This also limits the capability to observe temperature gradients in the TEM specimen. With the increase of temperature, the Raman peak gets broader and weaker because the interatomic bonds become softer, and the corresponding temperature uncertainty increases. Picher et al. (Picher et al., 
2015) describe a maximum operative temperature of $600^{\circ} \mathrm{C}$, because the black body emission from the specimen interacted strongly with the data acquisition.

\section{Thermal diffuse scattering}

Principle

Inelastic phonon excitation in a TEM causes electrons to be scattered to high angles when they interact with the specimen. The energy transfer from electrons to the specimen is reflected by an increase of temperature in the latter. This phenomenon is called thermal diffuse scattering (TDS). This effect was first implemented inside a TEM by Takaoka et al. (Takaoka \& Katsumi, 1990) to measure the temperature change of a micro-area of Ge polycrystalline films by measuring the variation of the central spot beam intensity with temperature in diffraction mode. They used both a laser beam integrated into a TEM to heat the specimen fast and at high temperatures $\left(\geq 1000^{\circ} \mathrm{C}\right)$ and a heating holder. In both cases, they observed a correspondence between the specimen temperature change and the beam intensity variation. The experiment was later repeated finding an empirical formula that could relate the thickness of the specimen with the temperature variation and the transmittivity by referring to the two-beam approximation. A similar experiment was performed by Ohishi (Takaoka \& Katsumi, 1990) on Au thin films. Here, the variation in the intensity of the electron diffraction pattern was evaluated, and its background intensity was related to the change of the TDS intensity. A systematic investigation with nanometer spatial resolution was performed by He et al. (He \& Hull, 2012). With the use of single crystal Ge and Si, these authors were able to measure temperature changes as small as $5^{\circ} \mathrm{C}$. The analyzed region is determined by the size of the selected area aperture, 
since the experiment was conducted in diffraction mode (Takaoka \& Katsumi, 1990). This means that local temperature measurements are possible with this method.

\section{Challenges}

In case of single crystal material, heating may cause the specimen to bend by thermal expansion affecting the intensity of the central beam under analysis. By using polycrystalline material, this effect can be mitigated, since many grains are included if the measured area is large enough. The thickness of the specimen influences the variation in TDS intensity. Therefore, the thickness has to be measured in order to calculate the real effect of temperature on the TDS intensity. For a thick specimen, or one with high atomic mass, electrons can be scattered at large angles and exceed the maximum collection angle (He \& Hull, 2012). Measuring the thickness of the specimen in the exact region where it is heated could represent a challenge. Ohishi et al. (Ohishi et al., 1995) used an empirical formula based on a two-beam approximation theory to estimate the unknown thickness. He et al. used convergent beam electron diffraction (CBED) to measure it with an accuracy varying from $5 \%$ to $12 \%$.

\section{Plasmon signal change}

Principle

It is well-known that an increase in temperature for most materials leads to volume expansion. Such an expansion will lead to a change in the electron density, which again will change the collective plasma oscillation. Therefore, a change in temperature can be observed by electron-energy-loss spectroscopy (EELS) as a change in the plasmon energy (Shen et al., 2019). The thermal expansion changes the number density $(n)$ following the expression (Mecklenburg et al., 2017): 


$$
n(T) \simeq n\left(T_{0}\right)[1-3 f(T)]
$$

Where $n\left(T_{0}\right)$ is the electron density at the initial temperature $T_{0}$, and $f$ the integral of the coefficient of linear expansion $\alpha$ within a temperature variation, according to:

$$
f(T) \equiv \int_{T_{0}}^{T} \alpha\left(T^{\prime}\right) \mathrm{d} T^{\prime} \simeq \alpha_{1} \Delta T+\alpha_{2} \Delta T^{2}
$$

In the free electron model, the plasmon energy is linked to the energy density by:

$$
E=\hbar \omega_{p}=\hbar \sqrt{\frac{4 \pi n e^{2}}{m}}
$$

The change in plasmon energy can be normalized as $R \equiv\left[E(T)-E\left(T_{0}\right)\right] / E\left(T_{0}\right)$, and it can be related to the temperature change $\Delta T$ by a quadratic equation with the following solution (Mecklenburg, 2015):

$$
\Delta T=T-T_{0}=\frac{\alpha_{1}}{2 \alpha_{2}}\left(\sqrt{1-\frac{8 R \alpha_{2}}{3 \alpha_{1}^{2}}}-1\right)
$$

By measuring $R, \Delta T$ can be estimated. The effect was first measured with high resolution EELS by Abe et al. (Abe et al., 1992). (Mecklenburg et al., (2015) used EELS to measure the temperature variation of a chip heated with an aluminum serpentine through analysis of the plasmon peak shift (Figure 10). This method provides temperature measurements with a nanometer-scale spatial resolution, without the introduction of external compounds. The measured plasmon energy variation was related to the temperature of a Si nanoparticle (Mecklenburg et al., 2017). 
Choice of materials

The method can be performed for common metals and semiconductors such as: tungsten, silver, silicon, gallium arsenide, and gallium nitride, since they have sufficiently sharp plasmon resonances (Egerton, 2009). Unique for this method is that it can also be used to assess the local temperature of gases (Vendelbo et al., 2013).

Challenges

For temperature measurements of solid materials, a relatively thin specimen is needed $(<100 \mathrm{~nm})$. The use of EELS to measure the gas temperature is limited to closed-cell types of heating holders and cannot be applied in a TEM with a differentially pumped vacuum system. The EELS signal will be influenced by the larger volume around the specimen over which there will be temperature gradients from the warmest spot to the temperature of the column (Mølgaard et al., 2015).

\section{Phonon signal}

Principle

The electron-energy-loss spectrometer resolution with new monochromators has become sufficiently high to measure the phonon signal directly. This signal is observed as gain and loss on both sides below ca. $100 \mathrm{meV}$ from the center of the zero loss peak (Lagos \& Batson, 2018, Idrobo et al., 2018). The temperature is correlated with the gain-to-loss signal ratio (Idrobo et al., 2018). The principle of detailed balancing (PDB) can be used to determine the temperature from the measured phonon spectrum. This principle says that for a system in thermal equilibrium each process of energy gain should be balanced by a process of energy loss. This can be described by (Lagos \& Batson, 2018):

$$
\frac{P(\Delta q, \Delta E)}{P(-\Delta q,-\Delta E)}=e^{1 / K_{B} T^{\cdot \Delta E}}
$$


where $P(\Delta q, \Delta E)$ and $P(-\Delta q,-\Delta E)$ are the probabilities of gain and loss in momentum, $\Delta q$ and energy, $\Delta E$, respectively. $T$ is temperature and $K_{B}$ the Boltzmann constant. Plotting the logarithm to the measured gain-toloss ratio as a function of energy will, therefore, give a linear relation with $1 / K_{B} T$ as the slope.

An advantages of the method is that it offers very high accuracy with precisions down to ca. $\pm 1{ }^{\circ} \mathrm{C}$. The spatial resolution can also be extremely good, approaching $2 \AA$, according to Lagos \& Batson (Lagos \& Batson, 2018).

\section{Challenges}

To performan this temperature calibration, one needs a monochromated beam and a spectrometer that together offer an energy resolution of a few meV.

\section{Challenges for TEM temperature calibrations}

\section{Electron beam effects}

Beside the furnace in the TEM heating holder, the specimen is also heated by the interaction with the electron beam. In the context of temperature measurements, this is an obvious artifact to consider (Baker \& Harris, 1972; Egerton et al., 2004). Beam heating effects can be difficult to measure (Reimer \& Christinhusz, 1965; Gessinger et al., 1968; Viswanath \& Ramanathan, 2013, Guo et al., 2014). Egerton et al. estimates the effect for a thin film sample (Egerton et al., 2004). Here, the heat deposited in the specimen per second is described as $I\langle E(\mathrm{eV})\rangle(t / \lambda)$, where $I$ is the beam current, $\langle E\rangle$ the average energy loss per inelastic collision, $t$ the specimen thickness, and $\lambda$ the mean free path for inelastic scattering. In the steady state, heat generation is balanced by heat loss to radial conduction through the specimen and to thermal radiation. According to Egerton et al. thermal radiation is generally negligible, and the heat generation term is in steady state equal to the radial heat conduction: 


$$
I\langle E(e V)\rangle(t / \lambda)=4 \pi \kappa t\left(T-T_{0}\right) /\left[0.58+2 \ln \left(2 R_{0} / d\right)\right]
$$

where $k$ is the thermal conductivity, $T$ the temperature including beam heating, $T_{0}$ the temperature before beam heating, $R_{0}$ the radial distance of the material with conductivity $\kappa$, and $d$ the diameter of the electron beam (Egerton et al., 2004). Because the thermal radiation is neglected, $t$ does, surprisingly, not influence the beam-induced temperature. Because of the logarithmic term, variations of $R_{0}$ and $d$ only influence the beam heating to a minor degree. Thermal conductivity, $k$ and the mean free path, $\lambda$ influence the beam heating more strongly. Egerton et al. calculate the beam heating for the example of a carbon film with the relatively low thermal conductivity, $k=1.6 \mathrm{~W} / \mathrm{m} / \mathrm{K}$ ( $\mathrm{HT}=200 \mathrm{kV}$, $\left.I=5 \mathrm{nA}, R_{0}=30 \mu \mathrm{m}\right)$ where the beam heating is ca. $0.5-1.5{ }^{\circ} \mathrm{C}$ with $d$ in the range of $0.2-1000 \mathrm{~nm}$ (Egerton et al., 2004). Using the same experimental conditions for an Ni film with $K=90.1 \mathrm{~W} / \mathrm{m} / \mathrm{K}$ the beam heating is calculated to be less than ca. $0.13^{\circ} \mathrm{C}$ for diameters in the same range. These estimations suggest that beam heating generally results in a temperature increase by a few degrees or less. However, this is only under the assumption of a thin film sample with constant $\kappa$. The temperature increases more for other geometries, for example where $\lambda$ is low for a specimen with a small interface area to a support material with a low $\kappa$. Guo et al., for example, were able to increase the temperature from $23^{\circ} \mathrm{C}$ to at least $68^{\circ} \mathrm{C}$ for a $\mathrm{VO}_{2}$ nanofiber by beam heating (Guo et al., 2014).

To minimize the effect beam heating, as well as beam-induced artefacts, the in situ experiment should be performed with the lowest possible electron beam current density. A thermal contact from the imaged regions to a good heat conductor also helps to distribute the additional heat (Baker \& Harris, 1972; Viswanath \& Ramanathan, 2013). 


\section{Temperature variations}

One thing is to determine the temperature of the furnace. Another is to determine the temperature of the interesting part of the sample. If the specimen is small compared to the heater, and the thermal conductivity is high, then it is likely that the temperature of the sample is similar to that of the heater. The conductivity of the specimen itself is important, since often in the vacuum environment almost all heat has to be transported through the specimen. The specimen may be a poor high conductor, and we may want to image a part that sticks out in vacuum with no support film in the image background. In this case, the specimen temperature can be lower than the measured temperature. In principle, we could apply one of the local temperature calibration methods to determine the temperature of exactly this piece of specimen before performing the actual in situ heating experiment. In practice, we will often prioritize to minimize the beam dose at the specimen regions to be used in the in situ experiment. In addition, we will usually also be limited in time for such an in situ TEM/STEM experiment. In praxis, the temperature calibration will usually be performed on a different part of the specimen, or even a different thermometric material, than the ones to be used in the experiment that the temperature is calibrated for.

\section{Conclusion}

The field of in situ TEM experiments involving heating is rapidly growing and so has the number of methods available for heating. To measure temperatures accurately can be challenging in almost any experiment, and this is also true in the case of TEM, where the heated region can be so small, that common probes for temperature measurements, such as thermocouples, cannot be applied. The measurements are often indirect and rely on correct calibrations, for example, relating the resistance 
of a heater with temperature. It is therefore important for the microscopist to have alternative methods to verify the temperature.

In this study, we reviewed different techniques used for temperature calibration inside a TEM. The most important characteristics are summarized in Table 1. This table can be utilized by in situ TEM users as a reference table for temperature calibration experiments in order to choose the best technique based on the specific temperature range under analysis and the material under study.

\section{Acknowledgments}

Funding from the Danish Research Council for Technology and Production Case No. 12-126194. We gratefully acknowledge financial support of this research from In Situ Transmission Electron Microscopy on Operating Electrochemical Cells (TEMOC) project, supported by the Danish Council for Independent Research grant no. DFF - 4005-00247. Part of this work was supported by Nagoya University microstructural characterization platform as a program of "Nanotechnology Platform" of the Ministry of Education, Culture, Sports, Science and Technology (MEXT), Japan.

\section{References}

Abe, H., Terauchi, M., Kuzuo, R., \& Tanaka, M. (1992). Temperature Dependence of the VolumePlasmon Energy in Aluminum. J. Electron. Mater. 41, 465-468.

Agar, A. W. \& Lucas, J. H. (1962). Use of a new heating stage for the electron microscope. In Electron Microscopy, Fifth international congress for electron microscopy, Breese, S. S., (Eds.), pp. E-2. Philadelphia, Pennsylvania: Academic Press 
Alam, S. B., Panciera, F., Hansen, O., Mølhave, K. \& ROSS, F. M. (2015). Creating New VLS Silicon Nanowire Contact Geometries by Controlling Catalyst Migration. Nano Lett. 15, 6535-6541.

Allard, L. F., Bigelow, W. C., Jose-Yacaman, M., Nackashi, D. P., Damiano, J. \& Mick, S. E. (2009). A new MEMS-based system for ultra-high-resolution imaging at elevated temperatures. Microsc. Res. Tech. 72, 208-215.

Allen, G. L., Bayles, R. A., Gile, W. W. \& Jesser, W. A. (1986). Small particle melting of pure metals. Thin Solid Films 144, 297-308.

Asoro, M. A., Kovar, D., Shao-Horn, Y., Allard, L. F. \& Ferreira, P. J. (2010). Coalescence and sintering of Pt nanoparticles: in situ observation by aberration-corrected HAADF STEM. Nanotechnology 21, 025701.

Baker R. T. K. and Harris, P. S. (1972). Controlled atmosphere electron microscopy, J. Phys. E 5, 793-797.

Baker, R. T. K., Thomas, C. \& Thomas, R. B. (1975). Continuous observation of the particle size behavior of platinum on alumina. J. Catal. 38, 510-513.

Banhart, F. (2008). In-situ electron microscopy at high resolution. Université de Strasbourg: World Scientific Publishing Co.

Bayat, N., Carlberg, T. \& Cieslar, M. (2017). In-situ study of phase transformations during homogenization of 6005 and 6082 Al alloys. J. Alloys Compd. 725, 504-509. 
Begtrup, G. E., Ray, K. G., Kessler, B. M., Yuzvinsky, T. D., Garcia, H. \& Zettl, A. (2007). Probing nanoscale solids at thermal extremes. Phys. Rev. Lett. 99, 1-4.

Bernal, R. A., Ramachandramoorthy, R., Espinosa, H. D. (2015). Double-tilt in situ TEM holder with multiple electrical contacts and its application in MEMS-based mechanical testing of nanomaterials. Ultramicroscopy 156, 23-28.

Bonneaux, J. \& Guymont, M. (1999). Study of the order-disorder transition series in AuCu by in-situ temperature electron microscopy. Intermetallics 7, 797-805.

Brintlinger, T., QI, Y., Baloch, K. H., Goldhaber-Gordon, D. \& Cumings, J. (2008). Electron thermal microscopy. Nano Lett. 8, 582-585.

Buffat, P. H. \& Borel, J. P. (1976). Size effect on the melting temperature of gold particles. Phys. Rev. A 13, 2287-2298.

Burke, M. G., Bertali, G., Prestat, E., Scenini, F. \& Haigh, S. J. (2017). The application of in situ analytical transmission electron microscopy to the study of preferential intergranular oxidation in Alloy 600. Ultramicroscopy 176, 46-51.

Butler, E. P. \& Hale, K. F. (1981). Dynamic experiments in the electron microscope. Practical Methods in Electron Microscopy volume 9. North-Holland; Amsterdam, Netherlands

Candini, A., Richter, N., Convertino, D., Coletti, C., Balestro, F., Wernsdorfer, W., Kläui, M., Affronte, M. (2015). Electroburning of few-layer graphene flakes, epitaxial graphene, and turbostratic graphene discs in air and under vacuum. Beilstein J. Nanotechnol. 6, 711-719. 
Chang, C. F., Chen, J. Y., Huang, C. W., Chiu, C. H., Lin, T. Y., Yeh, P. H. \& Wu, W. W. (2017). Direct Observation of Dual-Filament Switching Behaviors in $\mathrm{Ta}_{2} \mathrm{O}_{5}$-Based Memristors. Small 13, 1-7.

Chen, R., Jungjohann, K. L., Mook, W. M., Nogan, J. \& Dayeh, S. A. (2017). Atomic Scale Dynamics of Contact Formation in the Cross-Section of InGaAs Nanowire Channels. Nano Lett. 17, 2189-2196.

Chung, D. D. L. (1978). Structural Studies of Graphite Intercalation Compounds. J. Electron. Mater. 7, 189-210.

Chung, D. D. L. (1980). Graphite-halogens as temperature calibration standards for transmission electron microscopy. Rev. Sci. Instrum. 51, 932-934.

Cremons, D. R., Flannigan, D. J. (2016). Direct in situ thermometry: Variations in reciprocal-lattice vectors and challenges with the Debye-Waller effect. Ultramicroscopy 161, 10-16.

Crozier, P. A. \& Datye, A. K. (2000). Direct observation of reduction of PdO to Pd metal by in situ electron microscopy. Stud. Surf. Sci. Catal. 130, 3119-3124.

Diaz, R. E., Sharma, R., Jarvis, K., Zhang, Q. \& Mahajan, S. (2012). Direct observation of nucleation and early stages of growth of GaN nanowires. J. Cryst. Growth 341, 1-6.

Egerton, R. F. (2009). Electron energy-loss spectroscopy in the TEM. Rep. Prog. Phys. 72, 16502.

Egerton, R. F., Li, P. \& Malac, M. (2004). Radiation damage in the TEM and SEM. Micron 35, 399-409.

Fei, L., Lei, S., Zhang, W. B., Lu, W., Lin, Z., Lam, C. H., Chai, Y. \& Wang, Y. (2016). Direct TEM observations of growth mechanisms of two-dimensional $\mathrm{MoS}_{2}$ flakes. Nat. Commun. 7, 12206. 
Fujita, T., Guan, P., McKenna, K., Lang, X., Hirata, A., Zhang, L., Tokunaga, T., Arai, S., Yamamoto, Yuta, Tanaka, N., Ishikawa, Y., Asao, N., Yamamoto, Yoshinori, Erlebacher, J. \& Chen, M. (2012). Atomic origins of the high catalytic activity of nanoporous gold. Nat. Mater. 11, 775-780.

Gai, P. L., Sharma, R. \& Ross, F. M. (2008). Environmental (S)TEM Studies of Gas - Liquid - Solid Interactions under Reaction Conditions. MRS Bull. 33, 107-114

Gao, Y. \& Bando, Y. (2002). Carbon nanothermometer containing gallium. Nature 415, 6-7.

Gao, Y., Bando, Y., Liu, Z., Golberg, D. \& Nakanishi, H. (2003). Temperature measurement using a gallium-filled carbon nanotube nanothermometer. Appl. Phys. Lett. 83, 81-84.

Gessinger, G. H., Lenel, F. V. \& Ansell, G. S. (1968). Estimate of the Temperature Rise of Micron-Sized Silver Particles in the Electron Microscope due to Electron-Beam Heating. J. Appl. Phys. 39, 5593-5597.

Gong, N. W., Lu, M. Y., Wang, C. Y., Chen, Y. \& Chen, L. J. (2008). Au(Si)-filled B- $\mathrm{Ga}_{2} \mathrm{O}_{3}$ nanotubes as wide range high temperature nanothermometers. Appl. Phys. Lett. 92, 1-4.

Grinolds, M. S., Lobastov, V. A., Weissenrieder, J., Zewail, A. H. (2006). Four-Dimensional Ultrafast Electron Microscopy of Phase Transitions. P. Natl. Acad. Sci. USA. 103, 18427-18431.

Gualandris, F. (2017). In situ transmission electron microscopy on operative electrochemical cells. Copenhagen, Technical University of Denmark 
Guo, H., Khan, M. I., Cheng, C., Fan, W., Dames, C., WU, J. \& Minor, A. M. (2014). Vanadium dioxide nanowire-based microthermometer for quantitative evaluation of electron beam heating. Nat. Commun. 5, 1-5.

Han, H. L., Melaet, G., Alayoglu, S. \& Somorjai, G. A. (2015). In Situ Microscopy and Spectroscopy Applied to Surfaces at Work. ChemCatChem 7, 3625-3638.

Hansen, P. L., Wagner, J. B., Helveg, S., Rostrup-Nielsen, J. R., Clausen, B. S. \& Topsøe, H. (2002). AtomResolved Imaging of Dynamic Shape Changes in Supported Copper Nanocrystals. Science 295, 20532055.

Hansen, T. W. \& Wagner, J. B. (2016). Controlled Atmosphere Transmission Electron Microscopy. Switzerland, Springer

Harks, P. P. R. M. L., Mulder, F. M. \& Notten, P. H. L. (2015). In situ methods for Li-ion battery research: A review of recent developments. J. Power Sources 288, 92-105.

Hattar, K., Han, J., Saif, T., Robertson, I. M. (2004). Development and Application of a MEMS-Based In Situ TEM Straining Device for Ultra-Fine Grained Metallic Systems. Microsc. Microanal. 10, 50-51.

He, L. \& Hull, R. (2012). Quantification of electronphonon scattering for determination of temperature variations at high spatial resolution in the transmission electron microscope. Nanotechnology 23, 205705.

Heinemann, K. \& Poppa, H. (1976). Direct observation of small cluster mobility and ripening. Thin Solid Films 33, 237-251. 
Helveg, S., López-Cartes, C., Sehested, J., Hansen, P. L., Clausen, B. S., Rostrup-Nielsen, J. R., AbildPedersen, F. \& Nørskov, J. K. (2004). Atomic-scale imaging of carbon nanofibre growth. Nature 427, 426-429.

Holloway, K. \& Sinclair, R. (1988). High-resolution and in situ tem studies of annealing of Ti-Si multilayers. J. Less-Common Met. 140, 139-148.

Ida, K., Sugiyama, Y., Chujyo, Y., Tomonari, M., Tokunaga, T., Sasaki, K. \& Kuroda, K. (2010). In-situ TEM studies of the sintering behavior of copper nanoparticles covered by biopolymer nanoskin. J. Electron Microsc. 59, 75-80.

Idrobo, J. C., Lupini, A. R., Feng, T., Unocic, R. R., Walden, F. S., Gardiner, D. S., Lovejoy, T. C., Dellby, N., Pantelides, S. T., Krivanek, O. L. (2018). Temperature Measurement by a Nanoscale Electron Probe Using Energy Gain and Loss Spectroscopy. Phys. Rev. Lett. 120, 095901.

Jacobsson, D., Panciera, F., Tersoff, J., Reuter, M. C., Lehmann, S., Hofmann, S., Dick, K. A. \& Ross, F. M. (2016). Interface dynamics and crystal phase switching in GaAs nanowires. Nature 531, 317-322.

Jeangros, Q., Hansen, T. W., Wagner, J. B., Damsgaard, C. D. \& He, C. (2013). Reduction of nickel oxide particles by hydrogen studied in an environmental TEM. J. Mater. Sci. 48, 2893-2907.

Jeangros, Q., Hansen, T. W., Wagner, J. B., Dunin-Borkowski, R. E., Hébert, C., Van Herle, J. \& HesslerWyser, A. (2016). Energy-filtered environmental transmission electron microscopy for the assessment of solid-gas reactions at elevated temperature: $\mathrm{NiO} / \mathrm{YSZ}-\mathrm{H}_{2}$ as a case study. Ultramicroscopy 169, 1121. 
Kallesøe, C., Wen, C.-Y., Mølhave, K., Bøggild, P. \& Ross, F. M. (2010). Measurement of local Si-nanowire growth kinetics using in situ transmission electron microscopy of heated cantilevers. Small 6, 20582064.

Kamino, T. \& Saka, H. (1993). A newly developed high resolution hot stage and its application to materials characterization. Microsc. Microanal. M. 4, 127-135.

Keene, B. J. (1993). Review of data for the surface tension of pure metals. Int. Mater. Rev. 38, 157-192.

Kim, T., Bae, J., Lee, Jae-Wook, Shin, K., Lee, Joon-Hwan, Kim, M. \& Yang, C. (2015). Temperature Calibration of a Specimen-heating Holder for Transmission Electron Microscopy. Appl. Microsc. 45, 95100.

Lagos, M. J., Batson, P. E. (2018). Thermometry with Subnanometer Resolution in the Electron Microscope Using the Principle of Detailed Balancing. Nano Lett. 18, 4556-4563.

Lan, Y., Wang, H., Chen, G. \& Ren, Z. (2013). Internal Temperature Calibration at Nanoscale on in situ Heating High Resolution Transmission Electron Microscopy. Microsc. Microanal. 19, 498-499.

Lee, S., Hippalgaonkar, K., Yang, F., Hong, J., Ko, C., Suh, J., Liu, K., Wang, K., Urban, J. J., Zhang, X., Dames, C., Hartnoll, S. A., Delaire, O. \& Wu, J. (2017). Anomalously low electronic thermal conductivity in metallic vanadium dioxide. Science $355,371-374$.

Martin, C. J. \& Boyd, J. D. (1973). A method for calibrating a specimen-heating stage in the electron microscope. J. Phys. E 6, 21-22. 
Mecklenburg, M., Hubbard, W. A., White, E. R., Dhall, R., Cronin, S. B., Aloni, S. \& Regan, B. C. (2015). Nanoscale temperature mapping in operating microelectronic devices. Science 347, 629-633.

Mecklenburg, M., Zutter, B. \& Regan, B. C. (2017). Thermometry of Silicon Nanoparticles. Phys. Rev. Applied 9, 014005.

Mølgaard, P., Willum, T., Birkedal, J. \& Degn, A. (2015). Modeling of temperature profiles in an environmental transmission electron microscope using computational fluid dynamics. Ultramicroscopy $152,1-9$.

Nanda, K. K., Sahu, S. N. \& Behera, S. N. (2002). Liquid-drop model for the size-dependent melting of low-dimensional systems. Phys. Rev. A 66, 132081-132088.

Niekiel, F., Kraschewski, S. M., Müller, J., Butz, B. \& Spiecker, E. (2017). Local temperature measurement in TEM by parallel beam electron diffraction. Ultramicroscopy 176, 161-169.

Ortega, Y., Dieker, C., Jäger, W., Piqueras, J., Fernández, P. (2010). Voids, nanochannels and formation of nanotubes with mobile Sn fillings in Sn doped ZnO nanorods. Nanotechnology 21, 225604

Panciera, F., Norton, M. M., Alam, S. B., Hofmann, S., Mølhave, K. \& Ross, F. M. (2016). Controlling nanowire growth through electric field-induced deformation of the catalyst droplet. Nat. Commun. 7. 12271.

Pawlow, O. (1910). Ueber den Einflub der Oberflache einer festen Phase auf die latente Warme und die Temperatur des Schmelzens. Zeitschr. f. Chem. und Ind. der Kolloide 7, 37-39. 
Peng, Z., Somodi, F., Helveg, S., Kisielowski, C., Specht, P. \& Bell, A. T. (2012). High-resolution in situ and ex situ TEM studies on graphene formation and growth on Pt nanoparticles. J. Catal. 286, 22-29.

Picher, M., Mazzucco, S., Blankenship, S. \& Sharma, R. (2015). Vibrational and optical spectroscopies integrated with environmental transmission electron microscopy. Ultramicroscopy 150, 10-15.

Rackauskas, S., Jiang, H., Wagner, J. B., Shandakov, S. D., Hansen, T. W., Kauppinen, E. I. \& Nasibulin, A. G. (2014). In situ study of noncatalytic metal oxide nanowire growth. Nano Lett. 14, 5810-5813.

Reguer, A., Bedu, F., Nitsche, S., Chaudanson, D., Detailleur, B. \& Dallaporta, H. (2009). Probing the local temperature by in situ electron microscopy on a heated $\mathrm{Si}_{3} \mathrm{~N} 4$ membrane. Ultramicroscopy 110, 61-66.

Reimer, L. \& Christenhusz, R. (1965). Determination of Specimen Temperature. Lab. Invest. 14, 11581168.

Reiss, H., Mirabel, P. \& Whetten, R. L. (1988). Capillarity theory for the 'coexistence' of liquid and solid clusters. J. Phys. Chem. 92, 7241-7246.

Revina, A. A., Oksentyuk, E. V. \& Fenin, A. A. (2007). Synthesis and properties of zinc nanoparticles: The role and prospects of radiation chemistry in the development of modern nanotechnology. Prot. Met. 43, 554-559.

Roth, J. A., Olson, G. L., Jacobson, D. C. \& Poate, J. M. (1990). Kinetics of solid phase epitaxy in thick amorphous Si layers formed by MeV ion implantation. Appl. Phys. Lett. 57, 1340-1342. 
Sambles, J. R. (1971). An Electron Microscope Study of Evaporating Gold Particles: The Kelvin Equation for Liquid Gold and the Lowering of the Melting Point of Solid Gold Particles. P. Roy. Soc. A-Math. Phy. 324, 339-351.

Sharma, R.; Crozier, P. A. (2005). Environmental Transmission Electron Microscopy in Nanotechnology. In Handbook of Microscopy for Nanotechnology, Yao, N., Wang Z. L. (Eds.), pp. 531-565, Switzerland, Springer.

Shen, L., Mecklenburg, M., Dhall, R., Regan, B. C., Cronin, S. B. (2019). Measuring nanoscale thermal gradients in suspended MoS 2 with STEM-EELS. Appl. Phys. Lett. 115, 153108.

Simmons, R. O. (1970). Use of fcc metals as internal temperature standards in x-ray diffraction. J. Appl. Phys. 41, 2235-2240.

Simonsen, S. B. (2008). In situ studies of $\mathrm{CeO}_{2}$-catalyzed soot oxidation by means of Environmental Transmission Electron Microscopy. Copenhagen, University of Copenhagen

Simonsen, S. B., Agersted, K., Hansen, K. V., Jacobsen, T., Wagner, J. B., Hansen, T. W. \& Kuhn, L. T. (2015). Environmental TEM study of the dynamic nanoscaled morphology of NiO/YSZ during reduction. Appl. Catal. A-Gen. 489, 147-154.

Simonsen, S. B., Dahl, S., Johnson, E., Helveg, S. \& Johnson, E. (2009). Direct observations of $\mathrm{CeO}_{2}-$ catalyzed soot oxidation at the nano-scale using environmental transmission electron microscopy. SAE Int. J. Mater. Manuf. 1, 199-203. 
Simonsen, S. B., Chorkendorff, I., Dahl, S., Skoglundh, M. \& Helveg, S. (2016). Coarsening of Pd nanoparticles in an oxidizing atmosphere studied by in situ TEM. Surf. Sci. 648, 278-283.

Simonsen, S. B., Chorkendorff, I., Dahl, S., Skoglundh, M., Meinander, K., Jensen, T. N., Lauritsen, J. V. \& Helveg, S. (2012). Effect of particle morphology on the ripening of supported Pt nanoparticles. J. Phys. Chem. C 116, 5646-5653.

Simonsen, S. B., Shao, J. \& Zhang, W. (2017). Structural evolution during calcination and sintering of a $\left(\mathrm{La}_{0.6} \mathrm{Sr}_{0.4}\right)_{0.99} \mathrm{CoO}_{3-\delta}$ nanofiber prepared by electrospinning. Nanotechnology 28, 265402.

Sinclair, R. (2013). In situ high-resolution transmission electron microscopy of material reactions. MRS Bull. 38, 1065-1071.

Sinclair, R. \& Parker, M. A. (1986). High-resolution transmission electron microscopy of silicon re-growth at controlled elevated temperatures. Nature 322, 531-533.

Stach, E. A, Hull, R., Bean, J. C., Jones, K. S. \& Nejim, A. (1998). In Situ Studies of the Interaction of Dislocations with Point Defects during Annealing of Ion Implanted Si/SiGe/Si (001) Heterostructures. Microsc. Microanal. 4, 294-307.

Steinhauer, S., Wang, Z., Zhou, Z., Krainer, J., Köck, A., Nordlund, K., Djurabekova, F., Grammatikopoulos, P. \& Sowwan, M. (2017). Probing electron beam effects with chemoresistive nanosensors during in situ environmental transmission electron microscopy. Appl. Phys. Lett. 110, 094103. 
Suh, I. K., Ohta, H. \& Waseda, Y. (1988). High-temperature thermal expansion of six metallic elements measured by dilatation method and X-ray diffraction. J. Mater. Sci. 23, 757-760.

Swann, P. R. (1978). Specimen Device for In Situ Experiments. In Ninth International Congress on Electron Microscopy, Sturgess, J. M. (Eds.), pp. 319-329. Toronto: The Microscopy Society of Canada.

Taheri, M. L., Stach, E. A., Arslan, I., Crozier, P. A., Kabius, B. C., Lagrange, T., Minor, A. M., Takeda, S., Tanase, M., Wagner, J. B. \& Sharma, R. (2016). Current status and future directions for in situ transmission electron microscopy. Ultramicroscopy 170, 86-95.

Takaoka, A. \& Katsumi, U. (1990). Temperature measurement on micro-area of specimen in TEM by using thermal diffuse scattering effect. J. Electron Microsc. 39, 69-70.

Takashi, O., Daisuke, S., Kenji, H. \& Jun-Ichi, K. (1995). Evaluation of thermal diffuse electron scattering in Au with the imaging plate. Mater. Trans. 36, 686-688.

Thornburg, D. D. \& Wayman, C. M. (1973). Specimen temperature increases during transmission electron microscopy. Physica Status Solidi 15, 449-453.

Valdrè, U. \& Goringe, M. J. (1965). A liquid helium cooled goniometer stage for an electron microscope. J. Sci. Instrum. 42, 268-269.

Vendelbo, S. B., Kooyman, P. J., Creemer, J. F., Morana, B., Mele, L., Dona, P., Nelissen, B. J. \& Helveg, S. (2013). Method for local temperature measurement in a nanoreactor for in situ high-resolution electron microscopy. Ultramicroscopy 133, 72-79. 
Vijayan, S. \& Aindow, M. (2019). Temperature calibration of TEM specimen heating holders by isothermal sublimation of silver nanocubes. Ultramicroscopy 196, 142-153.

Viswanath, B. \& Ramanathan, S. (2013). Direct in situ observation of structural transition driven actuation in $\mathrm{VO}_{2}$ utilizing electron transparent cantilevers. Nanoscale 5, 7484-92.

Walsh, M. J., Yoshida, K., Gai, P. L. \& Boyes, E. D. (2009). In-situ heating studies of gold nanoparticles in an aberration corrected transmission electron microscope. J. Phys. Conf. Ser. 241, 012058.

Wang, C. M., Kwak, J. H., Kim, D. H., Szanyi, J., Sharma, R., Thevuthasan, S. \& Peden, C. H. F. (2006). Morphological evolution of $\mathrm{Ba}\left(\mathrm{NO}_{3}\right)_{2}$ supported on $\alpha-\mathrm{Al}_{2} \mathrm{O}_{3}(0001)$ : An in situ TEM study. J. Phys. Chem. B 110, 11878-11883.

Wang, Z. L. (2003). New developments in transmission electron microscopy for nanotechnology. Adv. Mater. 15, 1497-1514.

Wang, Z. L., Petroski, J. M., Green, T. C. \& El-Sayed, M. A. (1998). Shape Transformation and Surface Melting of Cubic and Tetrahedral Platinum Nanocrystals. J. Phys. Chem. B 102, 6145-6151.

Watanabe, H. (1956). Experimental evidance for the collective nature of the characteristic energy loss of electron in solids - studies on the dispersion relation of plasma frequency. J. Physical Soc. Japan 11, 112-119.

Williams, D. B. \& Carter, B. C. (2009). Transmission Electron Microscopy. Second Edition. Springer, New York 
Winterstein, J., Lin, P. A. \& Sharma, R. (2014). Measurement of local specimen temperature under flowing gas ambient in the environmental scanning transmission electron microscope (ESTEM) using diffraction. Microsc. Microanal. 20, 1596-1597.

Winterstein, J. P., Lin, P. A. \& Sharma, R. (2015). Temperature Calibration for In Situ Environmental Transmission Electron Microscopy Experiments. Microsc. Microanal. 21, 1-7.

Yang, Y., Fu, Z., Zhang, X., Cui, Y., Xu, F., Li, T., Wang, Y. (2019). In situ TEM mechanical characterization of one-dimensional nanostructures via a standard double-tilt holder compatible MEMS device. Ultramicroscopy 198, 43-48.

Yonezawa, T. (2009). In-situ observation of silver nanoparticle ink at high temperature. Biomed. Mater. Eng. 19, 29-34.

Yoshida, H., Kuwauchi, Y., Jinschek, J. R., Sun, K., Tanaka, S., Kohyama, M., Shimada, S., Haruta, M. \& Takeda, S. (2012). Visualizing Gas Molecules Interacting with Supported Nanoparticulate Catalysts at Reaction Conditions. Science 335, 317-319.

Zhang, L., He, M., Hansen, T. W., Kling, J., Jiang, H., Kauppinen, E. I., Loiseau, A. \& Wagner, J. B. (2017). Growth Termination and Multiple Nucleation of Single-Wall Carbon Nanotubes Evidenced by in Situ Transmission Electron Microscopy. ACS Nano 11, 4483-4493.

Zhang, Q., He, X., Shi, J., Lu, N., Li, H., Yu, Q., Zhang, Z., Chen, L.-Q., Morris, B., Xu, Q., Yu, P., Gu, L., Jin, K. \& Nan, C.-W. (2017). Atomic-resolution imaging of electrically induced oxygen vacancy migration and phase transformation in $\mathrm{SrCoO}_{2.5-\sigma .}$ Nat. Commun. 8, 104. 
Table 1 Summary of different techniques used for temperature calibration inside a TEM listed in this article. Only the best values to our knowledge, are considered. The temperature and resolution ranges refer to experimental results reported in the reference and not to theoretical limits

\begin{tabular}{|c|c|c|c|c|}
\hline Method & $\begin{array}{c}\text { Temperature } \\
\text { range }\end{array}$ & Uncertainty & $\begin{array}{l}\text { Spatial } \\
\text { resolution }\end{array}$ & $\begin{array}{c}\text { Applicable in gas } \\
\text { environment }\end{array}$ \\
\hline Melting point & $157-1083^{\circ} \mathrm{C}$ & $\begin{array}{l} \pm 5-25^{\circ} \mathrm{C} \text { (Vijayan } \\
\& \text { Aindow, 2019) }\end{array}$ & $\begin{array}{c}\text { Few } \\
\text { nanometers } \\
\text { (Vijayan \& } \\
\text { Aindow, 2019) }\end{array}$ & $\begin{array}{c}\text { Not in oxidizing } \\
\text { gases for melting } \\
\text { points above } \\
\text { oxidation } \\
\text { temperature }\end{array}$ \\
\hline $\begin{array}{c}\text { Crystal phase } \\
\text { structure } \\
\text { transition }\end{array}$ & $\begin{array}{l}\text { 40-100 C (Chung, } \\
\text { 1980; Guo et al., } \\
2014 \text { ) } \\
450-800{ }^{\circ} \mathrm{C} \text { (Sinclair } \\
\text { \& Parker, 1986; } \\
\text { Stach et al., 1998) }\end{array}$ & $\begin{array}{l} \pm 10^{\circ} \mathrm{C} \text { (Stach et } \\
\text { al., 1998, Chung, } \\
1980)\end{array}$ & $\begin{array}{c}\text { Few } \\
\text { nanometers } \\
\text { (Holloway \& } \\
\text { Sinclair, 1988) }\end{array}$ & $\begin{array}{l}\text { Reactive gases may } \\
\text { result in other } \\
\text { phase changes } \\
\text { than in vacuum }\end{array}$ \\
\hline $\begin{array}{l}\text { Magnetic } \\
\text { structure }\end{array}$ & $\begin{array}{l}368^{\circ} \mathrm{C} \text { (Martin \& } \\
\text { Boyd, 1973) and } \\
\text { potentially from } 40 \\
{ }^{\circ} \mathrm{C} \text { to } 1131^{\circ} \mathrm{C}\end{array}$ & Unknown & $\begin{array}{c}100 \mathrm{~nm} \\
\text { (Martin \& } \\
\text { Boyd, 1973) }\end{array}$ & $\begin{array}{l}\text { Reactive gases may } \\
\text { result in } \\
\text { transformations } \\
\text { influencing the }\end{array}$ \\
\hline
\end{tabular}




\begin{tabular}{|c|c|c|c|c|}
\hline & & & & magnetic \\
properties
\end{tabular}




\begin{tabular}{|c|c|c|c|c|}
\hline $\begin{array}{l}\text { Gas-solid } \\
\text { chemical } \\
\text { reactions }\end{array}$ & $\begin{array}{c}\text { 300-400 C } \\
\text { (Simonsen et al., } \\
\text { 2017) } \\
400-650^{\circ} \mathrm{C} \\
\text { (Kallesøe et al., } \\
\text { 2010) }\end{array}$ & $\begin{array}{c} \pm 10-30{ }^{\circ} \mathrm{C} \\
\text { (Kallesøe et al., } \\
\text { 2010) }\end{array}$ & $\begin{array}{c}\text { Few } \\
\text { nanometers } \\
\text { (Simonsen et } \\
\text { al., 2017; } \\
\text { Kallesøe et al., } \\
\text { 2010) }\end{array}$ & $\begin{array}{c}\text { Necessary. } \mathrm{O}_{2} \\
\text { (Simonsen et al., } \\
\text { 2017), } \mathrm{H}_{2} \\
\text { (Simonsen et al., } \\
\text { 2015) }\end{array}$ \\
\hline $\begin{array}{l}\text { Vibrational and } \\
\text { optical } \\
\text { spectroscopy }\end{array}$ & $\begin{array}{c}200-900^{\circ} \mathrm{C} \text { (Picher } \\
\text { et al., 2015) }\end{array}$ & $\begin{array}{l}\text { From } \pm 3 \text { to } 9{ }^{\circ} \mathrm{C} \\
\text { (Picher et al., } \\
\text { 2015) }\end{array}$ & $\begin{array}{l}\text { Limited by the } \\
\text { size of the } \\
\text { light probe. } \\
11 \pm 4 \text { in } \mu \mathrm{m} \\
\text { (Picher et al., } \\
\text { 2015) }\end{array}$ & Can be used \\
\hline $\begin{array}{c}\text { Thermal diffusion } \\
\text { scattering }\end{array}$ & $\begin{array}{l}\text { RT-900 C (Takaoka } \\
\text { \& Katsumi, 1990; } \\
\text { Ohishi et al., 1995; } \\
\text { He \& Hull, 2012) }\end{array}$ & $\begin{array}{c} \pm 5^{\circ} \mathrm{C}(\mathrm{He} \& \text { Hull, } \\
2012)\end{array}$ & $\begin{array}{l}\text { Limited by the } \\
\text { SAED } \\
\text { aperture. } 650 \\
\mathrm{~nm} \text { in (He \& } \\
\text { Hull, 2012) }\end{array}$ & Can be used \\
\hline Plasmon signal & $\begin{array}{c}\text { RT-1250 }{ }^{\circ} \mathrm{C} \\
\text { (Mecklenburg et } \\
\text { al., 2017; Vendelbo } \\
\text { et al., 2013) }\end{array}$ & $\begin{array}{l}\text { From } \pm 5 \text { to } 10^{\circ} \mathrm{C} \\
\text { (Vendelbo et al., } \\
\text { 2013) }\end{array}$ & $\begin{array}{c}\leq 10 \mathrm{~nm} \\
\text { (Mecklenburg } \\
\text { et al., 2017) }\end{array}$ & $\begin{array}{l}\text { Can be used, } \mathrm{H}_{2} \\
\text { Vendelbo et al., } \\
\text { 2013) }\end{array}$ \\
\hline
\end{tabular}




\begin{tabular}{|c|c|c|c|c|}
\hline Phonon signal & $\mathrm{RT}-1300^{\circ} \mathrm{C}$ & $\pm 1{ }^{\circ} \mathrm{C}$ & $2 \AA$ & Can be used \\
& (Idrobo et al., & (Lagos \& Batson, & (Lagos \& & \\
& $2018)$ & 2018) & Batson, 2018) & \\
\hline
\end{tabular}



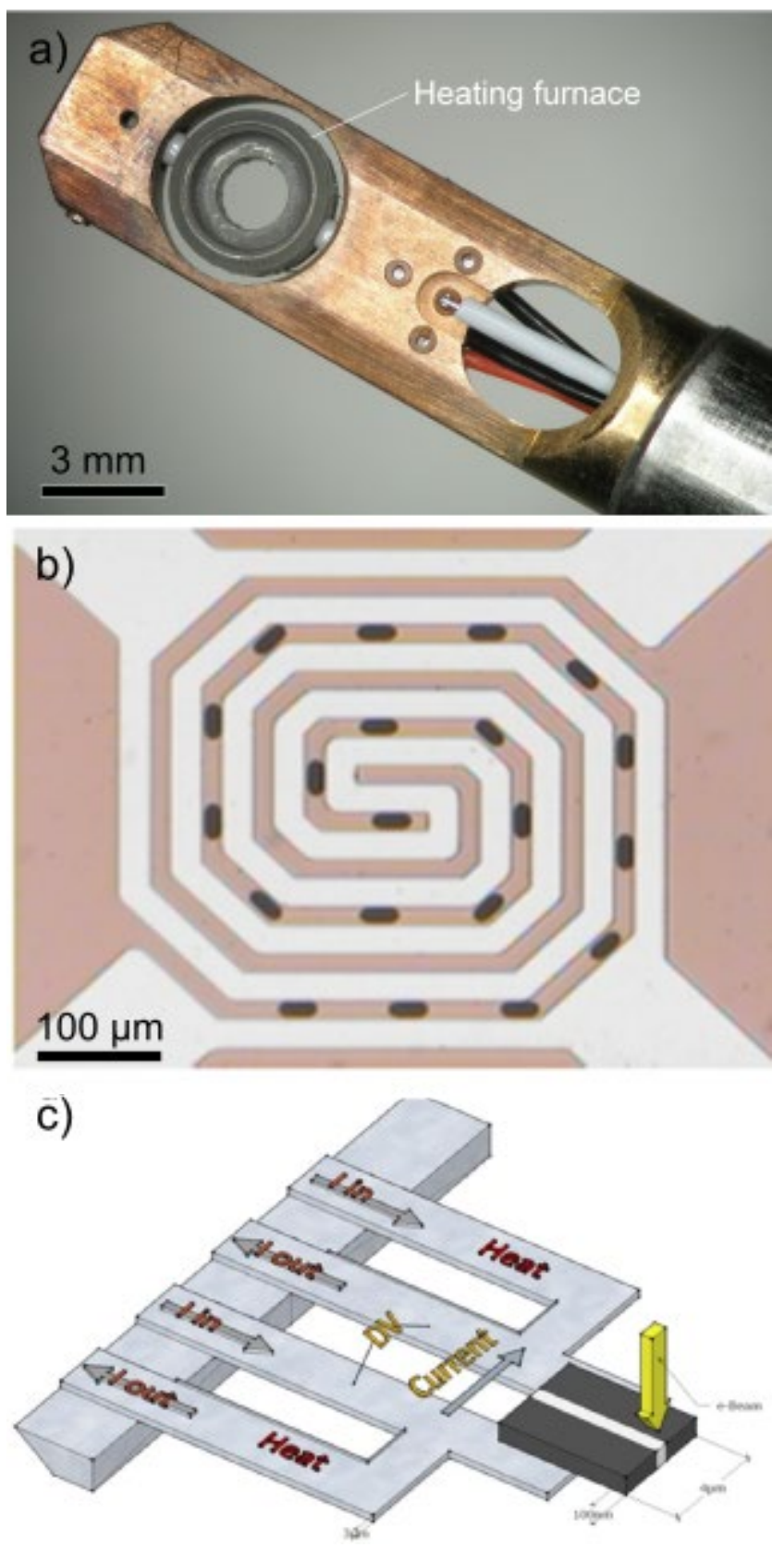

Figure 1: Different types of TEM/STEM heaters. a) Commercial traditional cup-type of holder where the furnace supports a standard 3-mm TEM/STEM grid. The temperature is raised by a heater filament and the temperature is monitored by thermocouples attached to the outer surface of the furnace. b) Central part of MEMS-based heating chip. The heater spiral can be seen. The small dark regions are electron-transparent windows. c) Sketch of an alternative chip-design for a MEMS-based 
heating holder developed at DTU (Kallesøe et al., 2010). Two isolated cantilever loops act as a heat source by Joule heating.

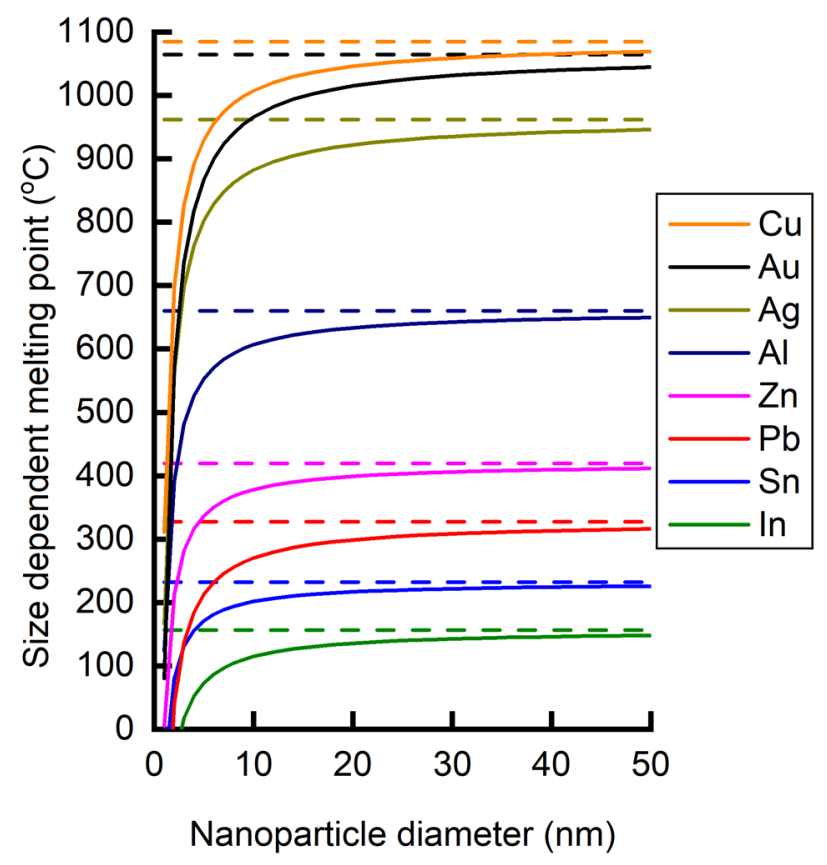

Figure 2: Particle size-dependency of the melting point for the pure elements presented in Figure 3. The size-dependencies are calculated based on equation 1. The dashed lines represent the bulk melting temperature for each element. Values for $\sigma$ are taken from Keene et al. (Keene, 1993). 


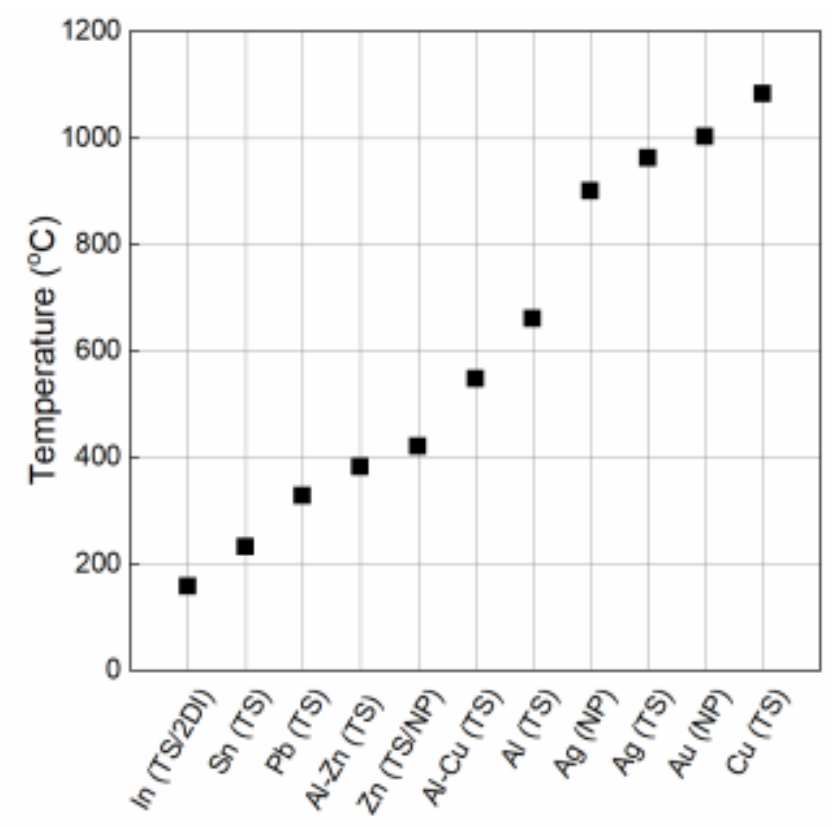

Figure 3: Melting points for metal and alloyed thin specimens (TS), nanoparticles (NP) and 2D islands (2DI) reported from TEM temperature calibration experiments. References are: In TS (Butler \& Hale, 1981), In 2DI (Brintlinger et al., 2008), Sn TS (Butler \& Hale, 1981; Kim et al., 2015), Pb TS (Butler \& Hale, 1981), Al-Zn TS (Swann, 1978), Al-95 wt\% Zn TS (Kim et al., 2015), Zn TS Butler \& Hale, 1981) Zn NP (Simonsen et al.; 2015), Al TS (Butler \& Hale, 1981; Kim et al., 2015; Stach et al., 1998), Ag NP (Simonsen et al.; 2015), Ag TS (Butler \& Hale, 1981), Au NP (Reguer et al., 2009; Begtrup et al., 2007), Cu TS (Butler \& Hale, 1981). 


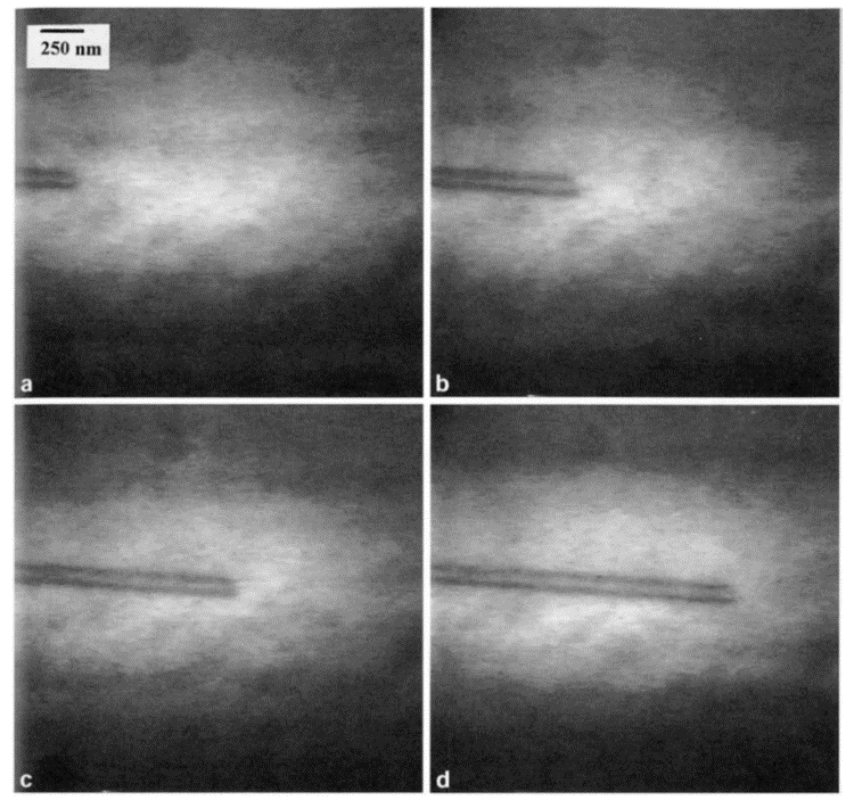

Figure 4: TEM time-sequence images (Stach et al., 1998), where the motion of a dislocation from a) to d) is recorded at constant temperature. Each frame was recorded with 1 second difference. The specimen is a SiGe followed by ion implantation in order to induce point defect formation.

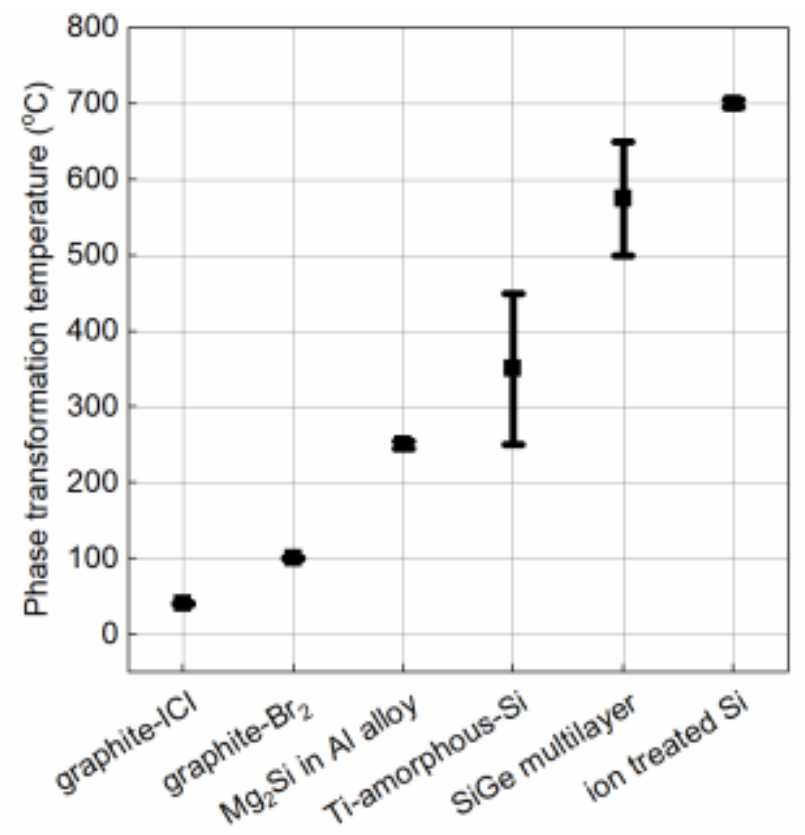


Figure 5: Examples of materials with phase transformation observed by TEM heating. The reported temperature range calibration is indicated for each material. References for the reports are: graphite-IC1, graphite-Br2 (Chung, 1980), Mg2Si in Al Alloy (Bayat et al., 2017), Ti-amorphous-Si (Holloway \& Sinclair, 1988), SiGe multilayer (Stach et al., 1998), ion treated Si (Sinclair \& Parker, 1986).

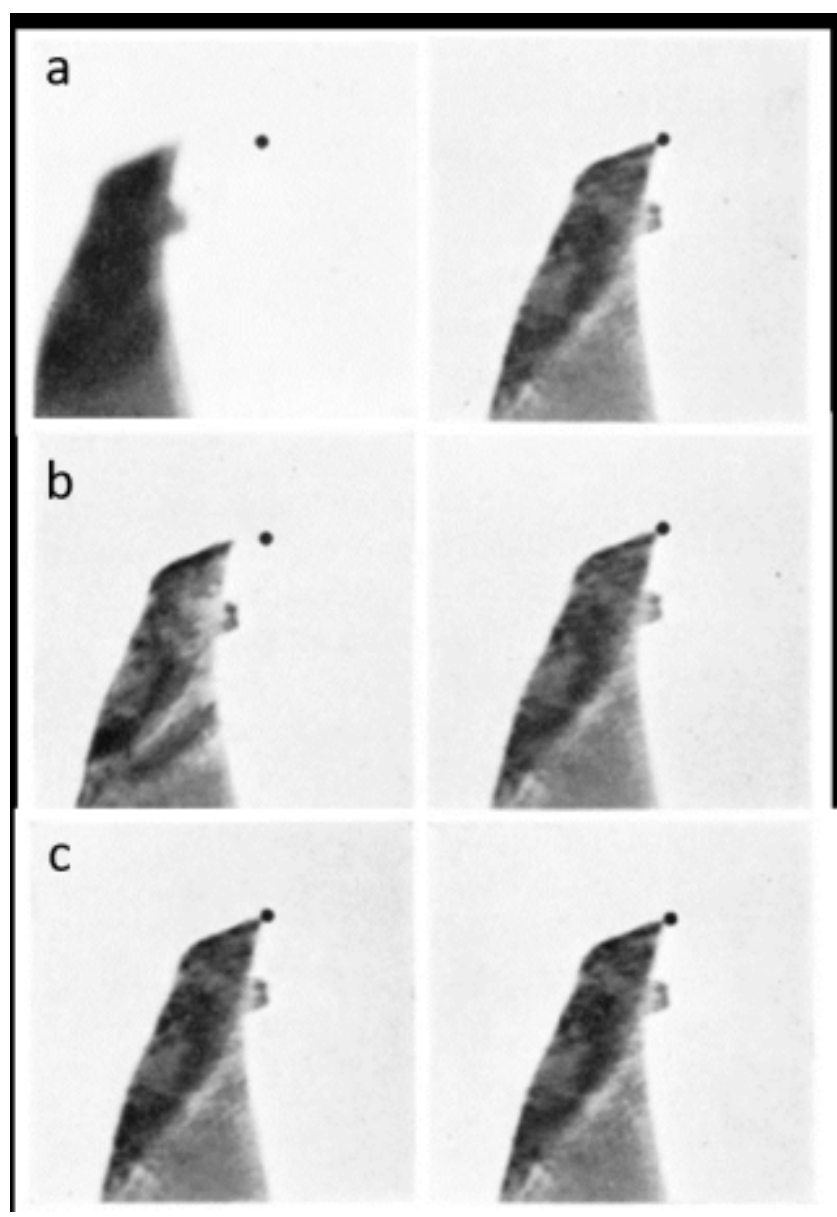

Figure 6: Pairs of TEM images of a ferromagnetic material recorded at different temperatures, one in focus and one over-focused (Martin \& Boyd, 1973). The magnetic field of the objective lens influences focusing until the Curie temperature is reached. A displacement is measured from the 
distance of the top part of the specimen with the black dot. In c), no displacement was measured, meaning that the Curie temperature for $\mathrm{Ni}$ in this case was reached $\left(368^{\circ} \mathrm{C}\right)$.

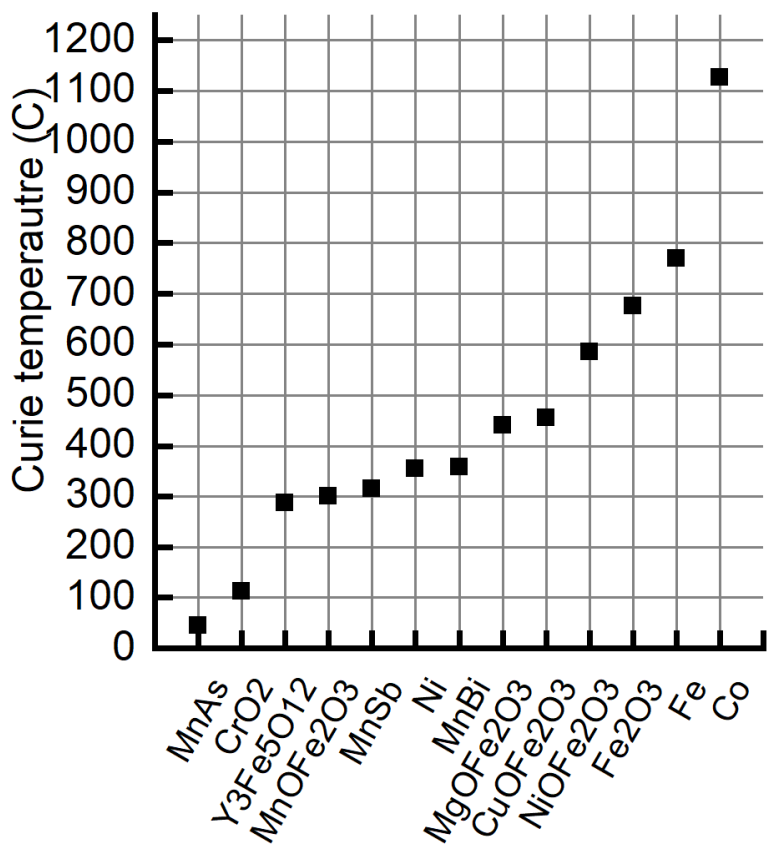

Figure 7: Curie points for selected materials
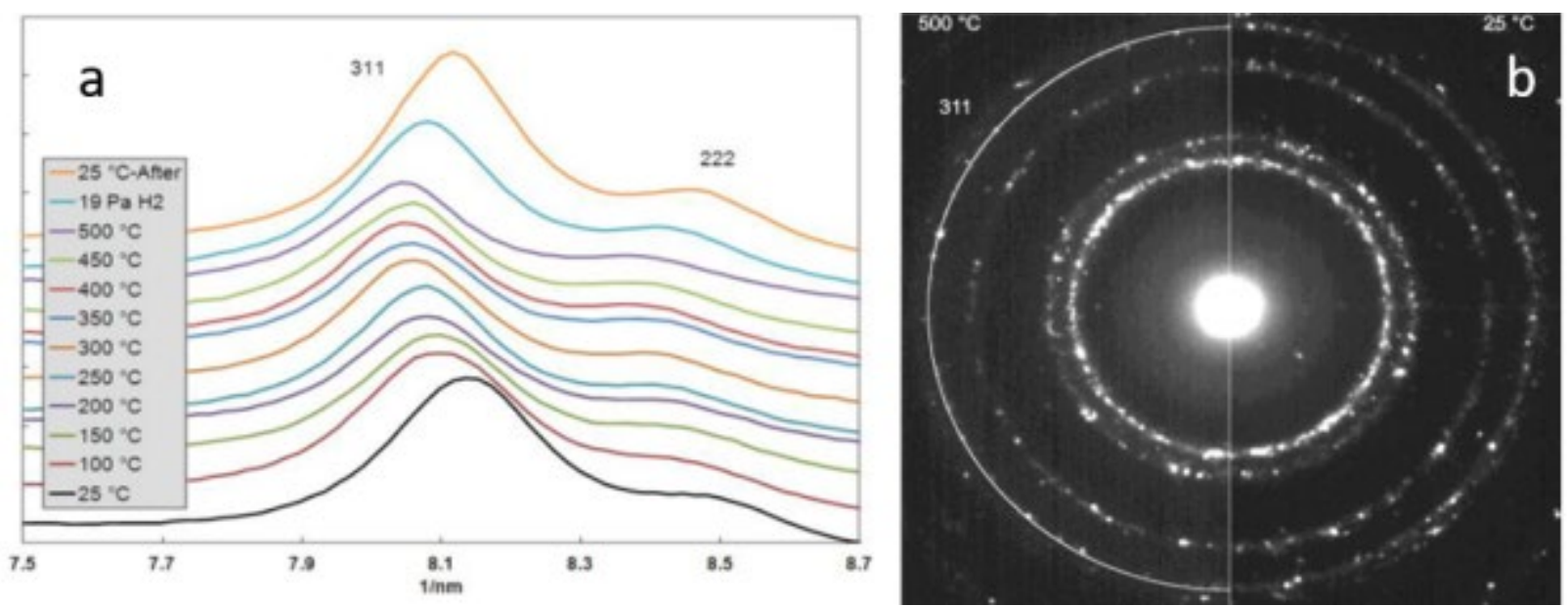

Figure 8: Analysis of lattice expansion reproduced from reference (Winterstein et al. 2014). a) Closeup on one peak in circular integration of electron diffraction patterns recorded at different 
temperatures. The peak shift indicates the temperature. b) Two examples for electron diffraction patterns, one at $500{ }^{\circ} \mathrm{C}$ and one at $25^{\circ} \mathrm{C}$.

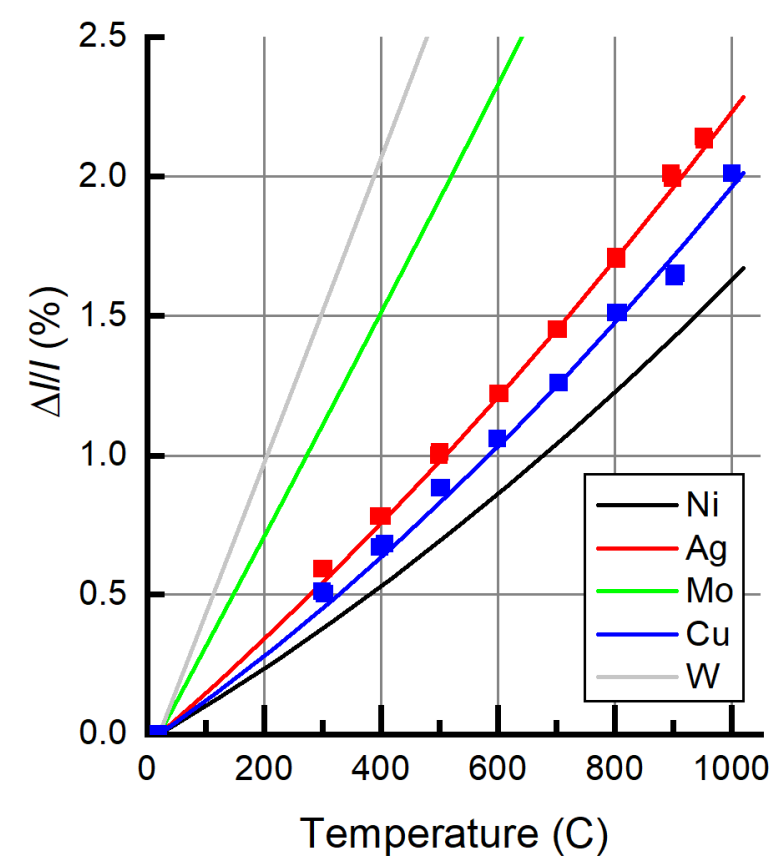

Figure 9: Linear lattice expansion calculated from equation 1 for a selection of metals, $\mathrm{Ni}, \mathrm{Ag}, \mathrm{Mo}$, $\mathrm{Cu}$ and W (lines) and lattice expansions for Ag and Cu (squares) measured by in situ XRD (Suh et al., 1988), presented as a function of temperature.

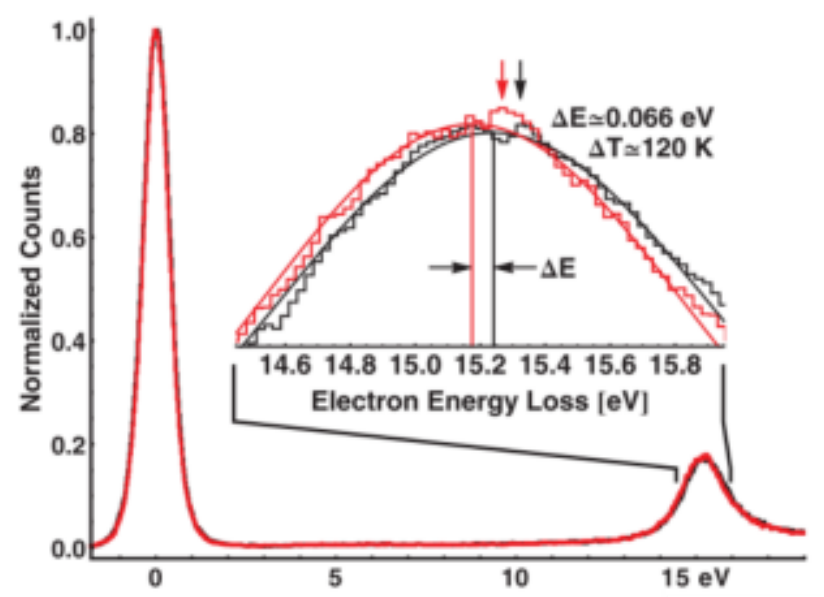


Figure 10: Aluminum EELS spectrum at $20^{\circ} \mathrm{C}$ (black) and $140{ }^{\circ} \mathrm{C}$ (red). The inset represents a close-up at the plasmon peak, where vertical lines indicate the plasmon peak center, as determined by curve fitting. The vertical arrows represent the peak maxima. The image is reproduced from Mecklenburg et al. (Mecklenburg et al., 2015). 